Check for updates

Cite this: RSC Adv., 2022, 12, 1287

Received 30th June 2021

Accepted 30th October 2021

DOI: $10.1039 / \mathrm{d} 1 \mathrm{ra05062a}$

rsc.li/rsc-advances

\section{The inchoate horizon of electrolyzer designs, membranes and catalysts towards highly efficient electrochemical reduction of $\mathrm{CO}_{2}$ to formic acid}

\begin{abstract}
P. Senthilkumar, (D) Mamata Mohapatra (D) * and Suddhasatwa Basu*
The economic viability of $\mathrm{CO}_{2}$ reactors is contingent on the selectivity of the $\mathrm{CO}_{2}$ reduction reaction and the rate of product formation. For this, the rational design of electrolyzers also has a substantial impact on the figures of merit (current density, faradaic efficiency, cell durability). Thus, herein we portray a short review on the shortcomings, challenges and the recent developments on different reactor configurations, components and membrane structures for the efficient electrochemical $\mathrm{CO}_{2}$ reduction $\left(\mathrm{CO}_{2} \mathrm{R}\right)$ into $\mathrm{HCOO}^{-} / \mathrm{HCOOH}$. Despite their low $\mathrm{CO}_{2}$ solubility and poor mass transport, $\mathrm{H}$-type electrolyzers are commercialized due to their screening of a vast number of catalysts. In contrast, membrane-based gas and liquid phase flow reactors break the barriers faced by $\mathrm{H}$-types through the incorporation of gas diffusion electrodes (GDEs) and the membrane electrode assembly (MEA). As the GDE forms the gas-liquid-solid interface, it allows the electrolyzers to generate current densities at the industrial level $\left(200 \mathrm{~mA} \mathrm{~cm}{ }^{-2}\right.$ ). Intriguingly, a continuous liquid fed intermittent flow electrolyzer can control the electrolyte flow at a desired frequency and allow sufficient time for $\mathrm{CO}_{2}$ gas molecules to effectively reduce into $\mathrm{HCOOH}$. Therefore, a high and stable faradaic efficiency (95\%) is achieved in $4 \mathrm{~h}$ for $\mathrm{HCOOH}(576.98 \mathrm{mg})$ using the boron-doped diamond catalyst. Very recently, a novel strategy to enhance the $\mathrm{CO}_{2} \mathrm{R}$ to $\mathrm{HCOO}^{-} / \mathrm{HCOOH}$ has been adopted via the recirculation of by-products to the liquid phase MEA flow reactors, which substantially improves $\mathrm{HCOO}^{-}$selectivity, lowers material costs, and promotes $\mathrm{CO}_{2}$ mass transfer. In the end, the zero-gap electrolyzer has newly emerged and affords
\end{abstract}

CSIR-Institute of Minerals and Materials Technology, Bhubaneswar, Odisha, India-751013.E-mail:sbasu@immt.res.in; sbasu@iitd.ac.in; mamata@immt.res.in

\section{P. Senthilkumar}

P. Senthilkumar presently is a senior project associate at Council of Scientific \& Industrial Research-Institute of Minerals and Materials Technology (CSIR-IMMT), Odhisa. He received his Ph.D. in Physics in 2020 under the mentorship of Prof. S. Dhanuskodi (Retd.) at Bharathidasan University, Tamil Nadu. His research interests across multidisciplinary areas in energy conversion such as photo/photocatalytic/electrochemical $\mathrm{CO}_{2}$ reduction, water splitting, electrolyzer designs, and density functional theory calculations.

\section{Mamata Mohapatra}

Dr Mamata Mohapatra received her Ph.D. from Utkal University, Bhubaneswar. She got her post-doctoral experience from University of Waterloo, Canada by availing BOYSCAST fellowship. She joined at Hydro \& Electrometallurgy department, CSIR-IMMT in 2006 (October) as Jr Scientist and has been undertaking research independently on the interdisciplinary field of research in the aqueous processing of ores and secondaries, synthesis and surface modification of transition metal oxide/oxalate and carbonate materials for environment and energy application. Currently, she is engaged in energy material development through the urban mining of sent batteries. She has many contributory well-cited publications in international peer review journals (about 85) in collaboration with IIT, Kanpur, Utkal University (India), KIIT, Murdoch University (Australia), and WATLab (Canada), University of Southern Denmark. Her work has received 3485 citations with an $h$ index of 27. She has successfully supervised 4 PhD students, 14 M.Sc students, 2 M.Tech students. 
reduced ohmic losses, leading to a straight-forward implementation of industrial systems for $\mathrm{CO}_{2} \mathrm{R}$ to value-added products in the future. Besides, the efficiency of $\mathrm{HCOO}^{-} / \mathrm{HCOOH}$ production is also explored against proton exchange, anion exchange and bipolar membranes, and the $\mathrm{pH}$ of the electrolyte plays a dominant role in deciding the stability and characteristics of the membranes. It is also depicted that the product selectivity depends on different electrolyzer configurations. Recently, bimetallic alloys ( $\mathrm{Bi}-\mathrm{Sn}, \mathrm{Bi}-\mathrm{In})$ and $2 \mathrm{D}$ layered composites $\left(\mathrm{SnO}_{2} / \mathrm{rGO} / \mathrm{CNT}\right)$ have proven to be potential electrocatalysts (faradaic efficiency $>95 \%$, highly selective and durable) assigned to the abundant active sites for $\mathrm{CO}_{2} \mathrm{R}$. Based on the recent findings and future research directions, we draw reader's attention to construct economic, scalable and energy-efficient $\mathrm{CO}_{2} \mathrm{R}$ electrolyzers to realize the technoeconomic predictions.

\section{Introduction}

A drastic rise in global population ( $\sim 7.9$ billion as of 2021$)$ and industrialization have brought a serious impact on humanity and the environment in the form of energy demand, global warming, and climate change. The heavy dependence of humankind on fossil fuels has pushed the energy consumption rate to 19.0 TW in 2019 and it will steadily increase in the coming century as the average energy consumption per person increases with the rise in the number of vehicles. ${ }^{1}$ On the other hand, a large part of global warming and climate change originates from the burning of carbon-based fossil fuels, releasing carbon dioxide $\left(\mathrm{CO}_{2}\right)$ into the atmosphere $(411.85 \mathrm{ppm}$ in 2019). ${ }^{2}$ According to the International Energy Agency,, ${ }^{3,4} \mathrm{CO}_{2}$ emission should be curtailed by at least $50 \%$ to keep the global temperature rise $<2{ }^{\circ} \mathrm{C}$ by 2050 . To mitigate the environmental footprint of current technologies and sort out the constraints of fossil fuels, solutions towards the projected growth of the

\section{Suddhasatwa Basu}

Prof. Suddhasatwa Basu completed his M.S. and Ph.D. from IISc, Bangalore prior to completing B.Tech. in Chemical Engineering from Calcutta University. He is Professor (on lien) at the Chemical Engineering Department, IIT Delhi. At present, he is the Director of CSIR-Institute of Minerals \& Materials Technology (IMMT), Bhubaneswar. He was earlier Associate Dean (R\&D), IIT Delhi and Head of Chemical Engineering Department, IIT Delhi. He has received Herdillia Award for Excellence in Basic Research in Chemical Engineering and A V Rama Rao Research Excellence Award and Indus Foundation award. He is a Fellow of The National Academy of Sciences of India (NASI), Indian Chemical Society. International Association of Advanced Materials, Sweden, Indian National Academy of Engineering, and Royal Society of Chemistry, $U K$. His current broad area of research consists of electrochemical, photoelectrochemical water splitting, high and low temperature fuel cells, electrolyzer, electrochemical sensor, micro fuel cell, artificial photosynthesis- $\mathrm{CO}_{2}$ reduction, batteries and supercapacitors. He has published 250 high impact journals articles with H-index 39. He has authored 10 books and book chapters and patented 5 technological innovations. He is the editor and editorial board member of many journals published by ACS, Springer-Nature and Taylor and Francis. energy crisis and environment pollution should adopt carbon neutral energy production and carrier systems. ${ }^{5}$ As a potential solution to these issues, $\mathrm{CO}_{2}$ capture and sequestration (CCS) and $\mathrm{CO}_{2}$ utilization (CCU) are frequently employed approaches to address the release of $\mathrm{CO}_{2}$ to the atmosphere. ${ }^{6}$ In CCS, the storage of $\mathrm{CO}_{2}$ is done with geological sub-surfaces/oceans; however, there is still the possibility of leakage into the atmosphere, and thus, CCU has become a prominent approach to overcome the above problems. Therefore, tremendous efforts are being made to recycle $\mathrm{CO}_{2}$ as renewable fuels and chemicals by the approach called as electrochemical reduction (ER), which decreases the $\mathrm{CO}_{2}$ emissions and also reduces the energy crisis (Fig. 1).

Three decades ago, Hori et al., studied electrochemical $\mathrm{CO}_{2}$ reduction $\left(\mathrm{CO}_{2} \mathrm{R}\right)$ on metal catalysts ${ }^{7,8}$ where the reaction took place at the electrode and electrolyte interface. The $\mathrm{CO}_{2} \mathrm{R}$ process involves the absorption of $\mathrm{CO}_{2}$ on the catalysts surface, transformation of protons or electrons to dissociate the $\mathrm{C}-\mathrm{H}$ bonds, and desorption of the final products from the electrode. Despite $\mathrm{CO}_{2} \mathrm{R}$ becoming an interdisciplinary research area between materials science, chemistry, and physics, it is still facing a series of technical challenges (enormous potential, low energy efficiency, etc.) before reaching commerciality. Unfortunately, the dissociation energy of the $\mathrm{C}=\mathrm{O}$ double bond is quite large $\left(750 \mathrm{~kJ} \mathrm{~mol}^{-1}\right)$ compared to $\mathrm{C}-\mathrm{H}\left(411 \mathrm{~kJ} \mathrm{~mol}^{-1}\right), \mathrm{C}-\mathrm{C}$ (336 $\left.\mathrm{kJ} \mathrm{mol}^{-1}\right)$, and $\mathrm{C}-\mathrm{O}\left(327 \mathrm{~kJ} \mathrm{~mol}^{-1}\right)$, making them energetically unfavorable in the absence of external catalysts. Without the electrocatalyst, the formation of the anion ${ }^{*} \mathrm{CO}_{2}{ }^{-}$ radical from $\mathrm{CO}_{2}$ via the first electron transfer requires a more negative cathodic potential of $-1.9 \mathrm{~V}$ vs. standard hydrogen electrode (SHE); hence, it is very much important to establish electrocatalysts to overcome the activation barrier and promote the reduction kinetics. ${ }^{9}$ Therefore, the efficiency and selectivity of the $\mathrm{CO}_{2} \mathrm{R}$ process depend on the electrocatalysts, local electrode potential, and the composition of the electrolytes. Although $\mathrm{CO}_{2} \mathrm{R}$ is observed with complex intermediates during diverse steps including electron and proton transfer, it is frequently accomplished with high overpotential (more negative potential must be biased than the theoretical potential to reduce $\mathrm{CO}_{2}$ ). This not only required additional energy but also gave undesirable competitive products $\left(\mathrm{H}_{2}\right)$, causing a decrease in both the efficiency and selectivity. Consequently, the reduction of the overpotential remains a major concern in the overall $\mathrm{CO}_{2} \mathrm{R}$ performance. 


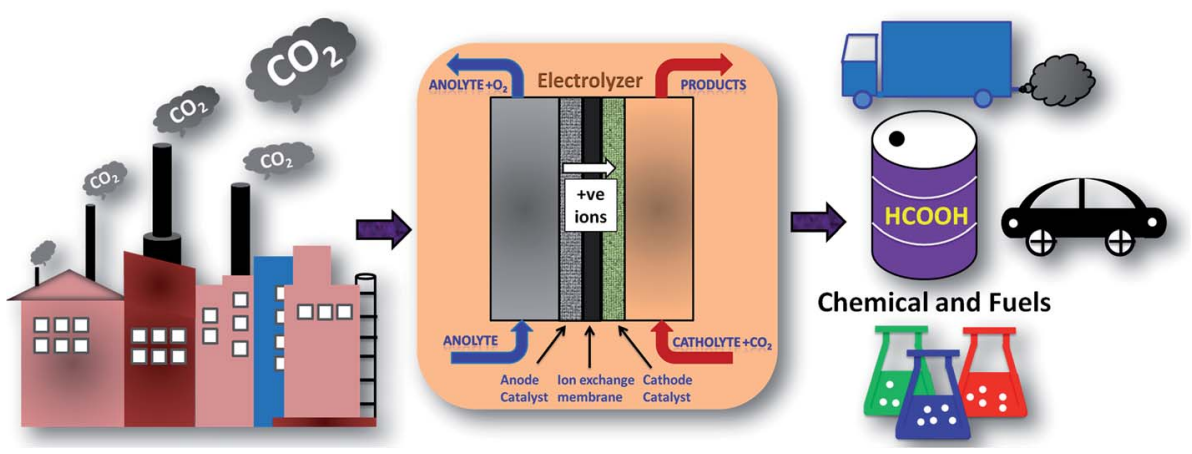

Fig. 1 Schematic representation of the electrochemical reduction of emitted $\mathrm{CO}_{2}$ to value-added products and fuels curtailing the energy crisis and environmental pollution.

Table 1 Illustration of thermodynamic potential $(E)$ of $\mathrm{CO}_{2} \mathrm{R}$ reactions against the aqueous solution yielding different products at $\mathrm{pH}=7$ and $25^{\circ} \mathrm{C}$ [ref. 12]

\begin{tabular}{ll}
\hline & $\begin{array}{l}E \\
(\mathrm{~V} v s .\end{array}$ \\
Thermodynamic half reactions for $\mathrm{CO}_{2}$ reduction & SHE) \\
\hline $\mathrm{CO}_{2}(\mathrm{~g})+2 \mathrm{H}_{2} \mathrm{O}(\mathrm{l})+2 \mathrm{e}^{-}=\mathrm{HCOOH}(\mathrm{l})+2 \mathrm{OH}^{-}$ & -0.610 \\
$\mathrm{CO}_{2}(\mathrm{~g})+5 \mathrm{H}_{2} \mathrm{O}(\mathrm{l})+6 \mathrm{e}^{-}=\mathrm{CH}_{3} \mathrm{OH}(\mathrm{l})+6 \mathrm{OH}^{-}$ & -0.380 \\
$\mathrm{CO}_{2}(\mathrm{~g})+6 \mathrm{H}_{2} \mathrm{O}(\mathrm{l})+8 \mathrm{e}^{-}=\mathrm{CH}_{4}(\mathrm{~g})+8 \mathrm{OH}^{-}$ & -0.240 \\
$2 \mathrm{CO}_{2}(\mathrm{~g})+10 \mathrm{H}_{2} \mathrm{O}(\mathrm{l})+14 \mathrm{e}^{-}=\mathrm{C}_{2} \mathrm{H}_{6}(\mathrm{~g})+14 \mathrm{OH}^{-}$ & -0.270 \\
$2 \mathrm{CO}_{2}(\mathrm{~g})+9 \mathrm{H}_{2} \mathrm{O}(\mathrm{l})+12 \mathrm{e}^{-}=\mathrm{C}_{2} \mathrm{H}_{5} \mathrm{OH}(\mathrm{l})+12 \mathrm{OH}^{-}$ & -0.33 \\
$2 \mathrm{CO}_{2}(\mathrm{~g})+8 \mathrm{H}_{2} \mathrm{O}(\mathrm{l})+12 \mathrm{e}^{-}=\mathrm{C}_{2} \mathrm{H}_{4}(\mathrm{~g})+12 \mathrm{OH}^{-}$ & -0.34 \\
$3 \mathrm{CO}_{2}(\mathrm{~g})+13 \mathrm{H}_{2} \mathrm{O}(\mathrm{l})+18 \mathrm{e}^{-}=\mathrm{C}_{3} \mathrm{H}_{7} \mathrm{OH}(\mathrm{l})+18 \mathrm{OH}^{-}$ & -0.320 \\
$\mathrm{CO}_{2}(\mathrm{~g})+3 \mathrm{H}_{2} \mathrm{O}(\mathrm{l})+4 \mathrm{e}^{-}=\mathrm{CH}_{2} \mathrm{O}(\mathrm{l})+4 \mathrm{OH}^{-}$ & -0.480 \\
$\mathrm{CO}_{2}(\mathrm{~g})+\mathrm{H}_{2} \mathrm{O}(\mathrm{l})+2 \mathrm{e}^{-}=\mathrm{CO}(\mathrm{g})+2 \mathrm{OH}$ & -0.520 \\
&
\end{tabular}

$\mathrm{CO}_{2} \mathrm{R}$ generates a variety of products due to the number of electrons transferred to the $\mathrm{CO}_{2}$ molecule and they are classified into one (oxalic acid $/ \mathrm{H}_{2} \mathrm{C}_{2} \mathrm{O}_{4}$ or oxalate $/ \mathrm{C}_{2} \mathrm{O}_{4}{ }^{2-}$ (ref. 1)), two (carbon monoxide/CO, ${ }^{7}$ formic acid/ $\mathrm{HCOOH}$ or formate/
$\mathrm{HCOO}^{-}$(ref. 1 and 5)), four (formaldehyde/ $\mathrm{CH}_{2} \mathrm{O}^{4}$ ), six (ethylene $/ \mathrm{CH}_{2} \mathrm{CH}_{2},{ }^{8}$ methanol $/ \mathrm{CH}_{3} \mathrm{OH},{ }^{10}$ ethanol $/ \mathrm{CH}_{3} \mathrm{CH}_{2} \mathrm{OH}^{11}$ ), and eight electron (methane/ $\mathrm{CH}_{4}$ (ref. 8)) pathways, and the corresponding thermodynamic half-reactions are illustrated in Table $1 .^{12}$ The economic viability of the aforementioned products has been assessed via the gross-margin model by Verma et $a .^{13}$ including the cost of goods sold and revenue; thereby, the figures of merit such as maximum potential, minimum current density, faradaic efficiency (FE), and electrocatalyst stability have been explored. Based on this model, it is predicted that the production of $\mathrm{HCOO}^{-}$or $\mathrm{HCOOH}$ and $\mathrm{CO}$ with an enriched operation voltage could be commercialized in the future over other products $\left(\mathrm{CH}_{4}, \mathrm{C}_{2} \mathrm{H}_{4}, \mathrm{CH}_{3} \mathrm{OH}\right.$, and $\left.\mathrm{C}_{2} \mathrm{H}_{5} \mathrm{OH}\right)$ due to the larger variation in the market size. Thus, $\mathrm{HCOOH}$ and $\mathrm{CO}$ derived from electrochemical $\mathrm{CO}_{2}$ reduction have more economic profitability, in which $\mathrm{HCOOH}$ in the context of fuel cell and energy carrier applications dominate CO because of its toxicity and environmental hazard. Formic acid is one of the foremost value-added products due to a number of factors. A large-scale $\mathrm{ER}$ of $\mathrm{CO}_{2}$ to formic acid is demonstrated to be feasible (Fig. 2a) as the price is about 1300 USD per ton, which is
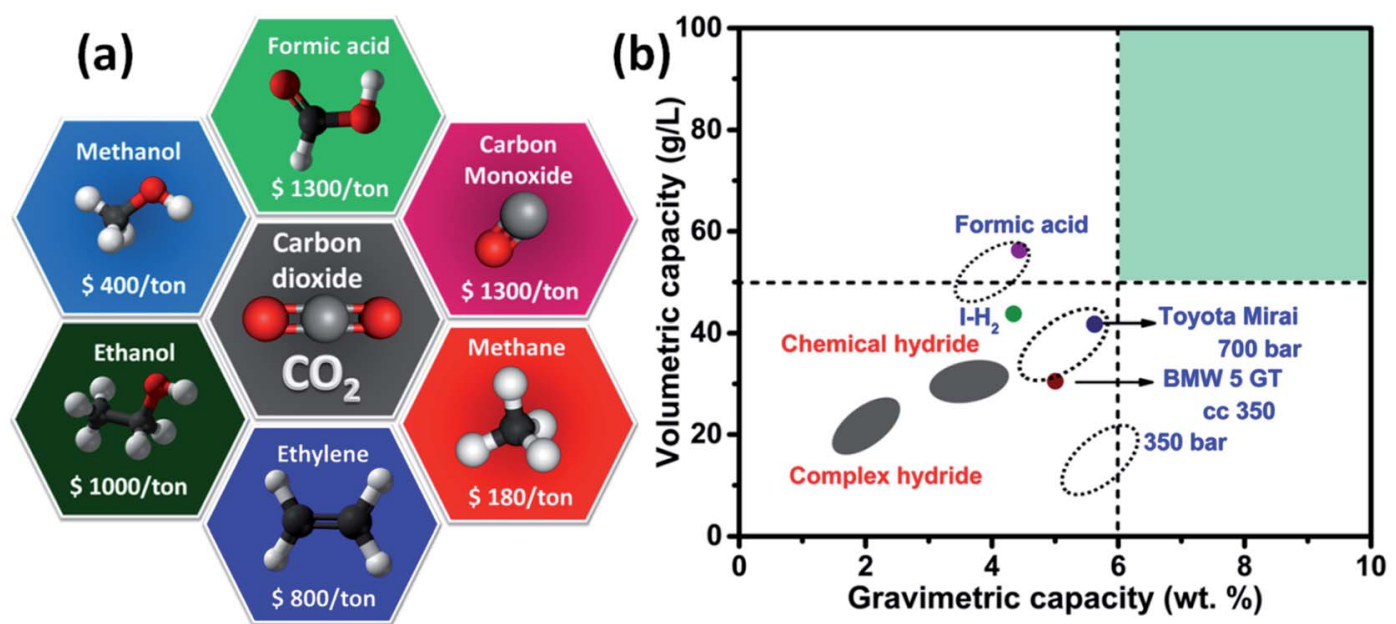

Fig. 2 (a) Global market price for $\mathrm{CO}_{2}$ reduced valuable commodity chemicals [ref. 12]. (b) FA as a hydrogen carrier overtakes other reversible hydrogen storage options [reproduced with permission from ref. 5, 15 and 16]. 
similar to that of carbon monoxide but much higher compared to methanol and ethylene. It is a simple carboxylic acid existing naturally and the global market price is estimated to hit 620 million dollars. ${ }^{\mathbf{1 4}}$ Formic acid is utilized in agriculture as a preservative agent due to the antibacterial property and also in fermentation processes, production of leather, and textile dyeing though it evaporates without leaving any surplus, unlike mineral acids. More importantly, formic acid can be used as a promising hydrogen carrier because of its $4.4 \mathrm{wt} \%$ of $\mathrm{H}_{2}$, high density $\left(1.22 \mathrm{~g} \mathrm{~cm}^{-3}\right)$, and volumetric capacity ( $53 \mathrm{~g} \mathrm{H}_{2}$ per L). The energy density of formic acid $\left(1.77 \mathrm{~kW} \mathrm{~h} \mathrm{~L}^{-1}\right)$ exceeds the commercial $70 \mathrm{MPa}$ hydrogen pressure tanks $\left(1.4 \mathrm{~kW} \mathrm{~h} \mathrm{~L}{ }^{-1}\right.$ for Toyota Mirai) so that it may find potential applications in automotive and mobile sectors (Fig. 2b). ${ }^{5}$ According to the techno-economic prediction by Spurgeon and Kumar, ${ }^{17}$ the deep capital cost inspection on the simple $\mathrm{C} 1$ chemicals $\left(\mathrm{HCOO}^{-}\right.$or $\mathrm{HCOOH}$ and $\left.\mathrm{CO}\right)$ could be profitable when the current density is well above $200 \mathrm{~mA} \mathrm{~cm}^{-2}$ and stable operation duration should be in the range of $20000 \mathrm{~h}$. However, the production of $\mathrm{HCOOH}$ and $\mathrm{CO}$ will be commercialized in the near future; this review deliberately focuses on the electrochemical reduction of $\mathrm{CO}_{2}$ to $\mathrm{HCOOH}$ and how the current density, faradaic efficiency, and stability are tuned by extracting the optimistic performance of various electrolyzers.

In recent years, extensive research has been conducted for the development of $\mathrm{CO}_{2} \mathrm{R}$ performance while taking care of the activity, energy efficiency, and long term stability but indeed noteworthy progress has been acquired on $\mathrm{HCOOH}$ production. For example, the grain boundary-enriched Bi catalyst showed a high current density ( $450 \mathrm{~mA} \mathrm{~cm}^{-2}$ ), FE (97\%), and stability $(100 \mathrm{~h})$ toward ultra-high concentration of $\mathrm{HCOOH}$ (up to $100 \mathrm{wt} \%) .{ }^{18}$ Han et al. ${ }^{19}$ observed $100 \% \mathrm{FE}$ at $-1.3 \mathrm{~V} v$ s. SCE for Bi nanosheet electrodes, whereas bismuth oxyiodides prepared by Wang et al. ${ }^{20}$ have shown high current density $\left(40 \mathrm{~mA} \mathrm{~cm}^{-2}\right)$ at $-0.9 \mathrm{~V}$ vs. $\mathrm{RHE}$ for $\mathrm{HCOO}^{-}$production. Besides, many continuous flow reactors deliver current density over $100 \mathrm{~mA}$ $\mathrm{cm}^{-2}$ and lifetime (h to a several months) with a high selectivity of $\mathrm{HCOO}^{-} / \mathrm{HCOOH}$ products. Despite these efforts, $\mathrm{CO}_{2} \mathrm{R}$ is still lacking in the scale up and commercialization process owing to the slow kinetics of $\mathrm{CO}_{2}$ reduction, large overpotential, and weak product selectivity as result of competitive hydrogen evolution reaction and the degradation of reactor performance over time. To take forward $\mathrm{CO}_{2} \mathrm{R}$ in a practically viable and efficient manner, the present technology needs a sudden migration from the half-cell or batch scale to continuous flow $\mathrm{CO}_{2}$ reactors, which overcome the existing issues such as poor mass transfer, solubility, low operation current density, and selectivity toward products. To address these issues, immense research interest has been dedicated to fundamental aspects of electrocatalyst fabrication, electrolyte composition, $\mathrm{pH}$, pressure, and temperature utilizing the lab scale reactors; ${ }^{\mathbf{1 0 2 1 - 2 3}}$ however, there is a lack of attention on reactor engineering, its components, membrane separators, and reaction mechanisms. ${ }^{24,25}$ Hence, one should explore $\mathrm{CO}_{2} \mathrm{R}$ reaction kinetics with respect to the electrolyzer configurations as they govern the local reaction environment near the electrode. Although there are few review and perspective articles exploring the $\mathrm{CO}_{2} \mathrm{R}$ of value-added products, the conversion of $\mathrm{CO}_{2}$ to $\mathrm{HCOOH} /$ $\mathrm{HCOO}^{-}$is still at an initial stage accompanied with key challenges, which have to be addressed toward the implementation of the commercial devices. Herein, we depart from the literature by exploring the recent advances in the reactor configurations, operating principles, and suitability of membranes and electrocatalysts to the scientific community.

\section{2. $\mathrm{CO}_{2} \mathrm{R}$ reactor configurations}

In order to enhance the figures of merit (current density, FE, and stability) and to address the major shortcomings (ohmic loss, mass transport, and solubility), the $\mathrm{CO}_{2} \mathrm{R}$ reactor engineering is an indispensible strategy since the reaction takes place between the open circuit potential of the cell and the applied external voltage. Recently, the extensive research has enabled the different geometries of electrolyzers (H-type, flow, and microfluidic reactors) and major components (gas diffusion electrode and membrane electrode assembly). In the present section, the current research updates and existing challenges of various electrolyzers toward $\mathrm{CO}_{2} \mathrm{R}$ to $\mathrm{HCOO}^{-}$/ $\mathrm{HCOOH}$ have been emphasized.

\subsection{H-type reactors}

However, H-type reactors (Fig. 3) are commercially available lab scale reactors for $\mathrm{CO}_{2} \mathrm{R}$ due to its adaptability with different electrodes and geometries, and ease of operation, leading to rapid and economic assessment. The cell consists of two compartments prefilled with the electrolyte in which the working and reference electrodes occupy the cathodic compartment, whereas the counter electrode lies at the anodic compartment. The ion exchange membrane connects these compartments via the channel, exposing the H-form; thereby, it prevents the reduced products from further oxidation by limiting the fuel crossover. $\mathrm{CO}_{2}$ gas is fed into the cathodic chamber wherein gas and liquid products can be collected after the reduction reaction. On the other hand, oxidation (oxygen evolution reaction with water) happens at the anodic chamber

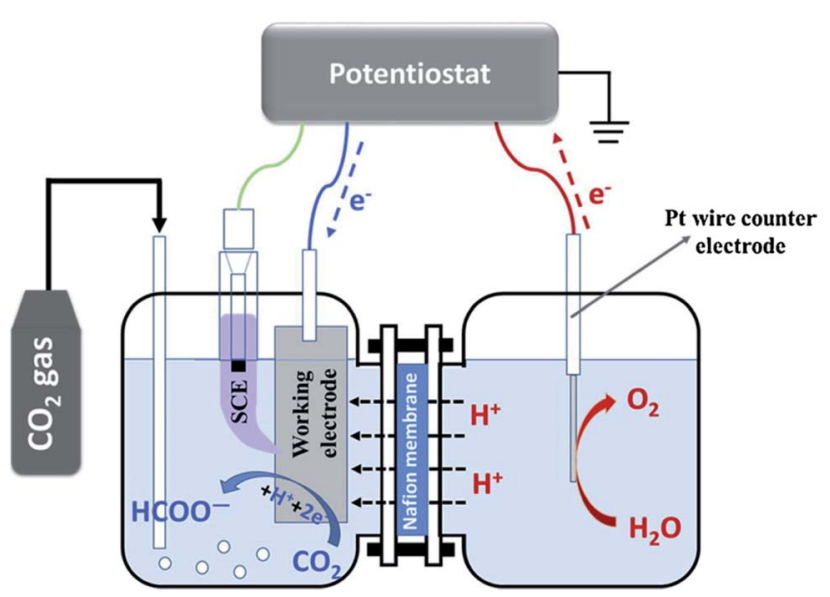

Fig. 3 Schematic illustration of a conventional $\mathrm{H}$-type cell for $\mathrm{CO}_{2}$ conversion to formic acid/formate [ref. 28, Copyright (C) 2019 Elsevier]. 

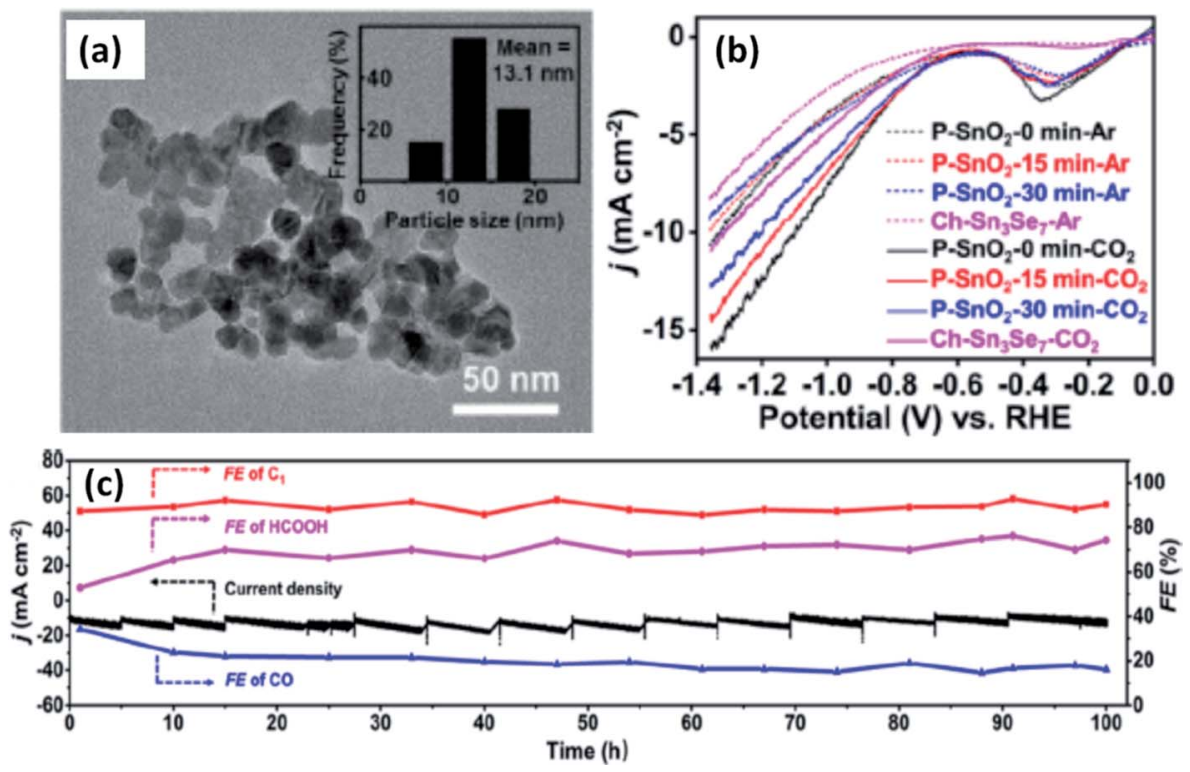

Fig. 4 (a) TEM picture of $\mathrm{SnO}_{2}$ particles in $\mathrm{P}-\mathrm{SnO}_{2}-0$ min, (b) $\mathrm{LSV}$ curves measured for $\mathrm{P}-\mathrm{SnO}_{2}$ samples for $\mathrm{CO}_{2}$ - $\mathrm{Saturated} 0.1 \mathrm{M} \mathrm{KHCO}$, (c) longterm catalytic test ( $100 \mathrm{~h}$ ) showing $\mathrm{FE}$ and the current density for $\mathrm{P}-\mathrm{SnO}_{2}-0$ min at $-1.06 \mathrm{~V}$ vs. RHE [ref. 26, Copyright @ 2021, American Chemical Society].

to maintain the charge balance by closing the circuit. H-type electrolyzers are capable of screening a number of catalysts in a short span of time, making it easy to operate and costeffective. Recently, Zhang et al. ${ }^{26}$ have employed an air tight $\mathrm{H}$-type electrolyzer with Nafion 117 membrane and porous $\mathrm{SnO}_{2}$ catalysts (Fig. 4a-c) have been loaded on carbon paper by drop casting. The optimal catalyst loading delivered the increased partial current density $\left(\sim 11.5 \mathrm{~mA} \mathrm{~cm}{ }^{-2}\right)$, a high faradaic efficiency $(94.5 \%)$, and excellent long-term stability $(100 \mathrm{~h})$ for the reduction of $\mathrm{CO}_{2}$ to $\mathrm{HCOOH}+\mathrm{CO}$. $\mathrm{Li}^{\prime}$ s group ${ }^{27}$ investigated both electrocatalytic (EC) and photoelectrocatalytic (PEC) $\mathrm{CO}_{2}$ reduction using $\mathrm{TiO}_{2}$ nanotube arrays as the photoanode and electrodeposited $\mathrm{CoO}_{x} @ \mathrm{Cu}$ foam as the cathode. The product yield of $\mathrm{HCOOH}$ at the potential from 0.5 to $0.9 \mathrm{~V} v$ s. $\mathrm{Ag} / \mathrm{AgCl}$ is 2 times higher for the photoanode-driven PEC system compared to the EC system at $0.6 \mathrm{~V} v s$. $\mathrm{Ag} / \mathrm{AgCl}$. The optimal performance for $\mathrm{CO}_{2} \mathrm{R}$ to $\mathrm{HCOOH}$ is obtained for the as-prepared $\mathrm{CoO}_{x}$ cathode with an $\mathrm{FE}$ of $60.9 \%$ at $-0.85 \mathrm{~V} v$ s. Ag/AgCl. Likewise, Sn catalysts on $\mathrm{Cu}$ film prepared by Wang et al. ${ }^{28}$ showed an initial current density of $0.9-1.4 \mathrm{~mA} \mathrm{~cm}^{-2}$ along with the maximum $\mathrm{FE}$ $91.7 \%$ at $-1.4 \mathrm{~V}$ vs. SCE in $\mathrm{CO}_{2}$ saturated $\mathrm{KHCO}_{3}$. When the reduction reaction time is increased, the $\mathrm{FE}$ declines to $81.6 \%$ for $2 \mathrm{~h}$ and further drops to $69.6 \%$ for $3 \mathrm{~h}$; therein, the current density declined to $0.7 \mathrm{~mA} \mathrm{~cm}{ }^{-2}$. This is attributed to the formation of the alkali metal intermetallic compound during $\mathrm{CO}_{2} \mathrm{R}$; meanwhile, the degradation of the $\mathrm{Sn}$ electrode commenced. Very recently, the ER of a $\mathrm{CO}_{2}$ electrolyzer bearing the boron-doped diamond (BDD) as the cathode has been used to achieve the best $\mathrm{HCOOH}$ selectivity. In this two-electrode $\mathrm{CO}_{2}$ electrolyzer, the reference electrodes are inserted on both the cathode and the anode compartments to monitor the actual potentials; therefore, the energy distribution in each part could be analyzed. Under the optimistic conditions, a remarkable FE
(96\%) at $3.5 \mathrm{~V}$ and the highest electrical-to-chemical energy (ECE) conversion efficiency (43\%) at $3 \mathrm{~V}$ were observed for FA, and the ECE further increased by $45 \%$ if $\mathrm{H}_{2}$ and CO products are included. ${ }^{29}$ One of the important targets in $\mathrm{CO}_{2} \mathrm{R}$ is to attain a single product with $100 \%$, which has not been frequently achieved; thus, H-type electrolyzers are still active for screening the numerous electrocatalysts. Despite this significant research progress, a vast amount of metal electrodes suffer from a lack of surface area, huge interelectrode distance, and poor reactor performance. Besides, a thick diffusion layer $(>50 \mu \mathrm{M})$ and low solubility $(0.034 \mathrm{M})$ of $\mathrm{CO}_{2}$ in aqueous electrolyte (dissolved $\mathrm{CO}_{2}$ rapidly forms neutral $\mathrm{pH}$ carbonate mixture in the alkaline electrolyte) lead to poor mass transport and selectivity. In order to increase the $\mathrm{CO}_{2}$ solubility, Li et al. ${ }^{30}$ fabricated the highpressure $\mathrm{H}$-type electrolyzer working at $60 \mathrm{~atm}$ of $\mathrm{CO}_{2}$ partial pressure, wherein the HER activity is almost quenched. The selectivity of $\mathrm{CO}_{2} \mathrm{R}$ is changed from complex $\mathrm{C}_{1}-\mathrm{C}_{3}$ products $(1$ atm) to single $\mathrm{C}_{1}\left(\mathrm{HCOO}^{-}\right)$product while exhibiting $\mathrm{FE}>98 \%$ at $45 \mathrm{~atm}$. These drawbacks limit the current density of the H-type electrolyzer below $100 \mathrm{~mA} \mathrm{~cm}{ }^{-2}$, which hinders the scaling up to the practical devices.

\subsection{Flow cell reactors}

To circumvent the shortcomings of the H-cell, flow cell reactors are developed in three different configurations (Fig. 5a-c), (i) gas phase, (ii) solid phase, and (iii) liquid phase reactors. ${ }^{31}$ From continuous flow reactors, the limitations experienced in $\mathrm{H}$-type cells prevailed, indicating a more realistic $\mathrm{CO}_{2} \mathrm{R}$ and ability to provide a current density more than $100 \mathrm{~mA} \mathrm{~cm}{ }^{-2}$. To begin, gas phase reactors employ the membrane electrode assembly (MEA) structure (a detailed explanation can be seen in the upcoming Section 2.4), which is made up of a catalyst coated 


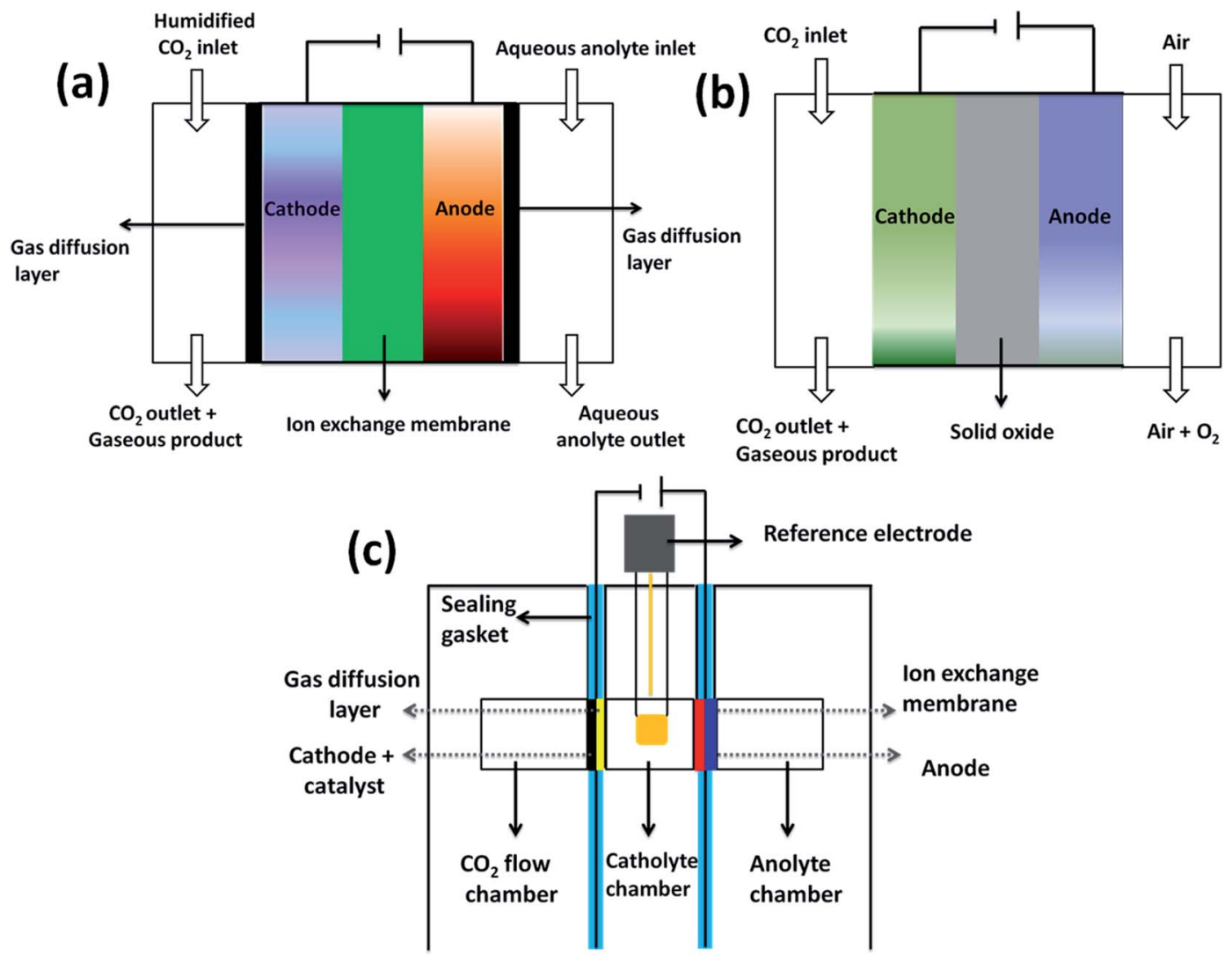

Fig. 5 (a) Gas phase reactor, (b) solid phase reactor, and (c) liquid phase reactor [reproduced from ref. 31, no permission is required].

on the gas diffusion electrode (GDE) as the cathode layer attached on an ion exchange membrane. Here, the solid polymer electrolyte is used as the membrane, which transports the ionic charges, enabling a continuous and a stable charge transfer in the circuit. $\mathrm{CO}_{2} \mathrm{R}$ takes place when humidified $\mathrm{CO}_{2}$ is supplied to the cathode and the source of water to the electrocatalyst is availed from the aqueous anolyte next to the MEA. Without the catholyte, there are some experimental results showing increased partial current density (PCD), higher stability, and better control over the liquid product toward formate production. ${ }^{32}$ The use of solid electrolytes in a gas phase flow reactor does not require the additional steps for final product separation as in the case of a liquid phase where the products are mixed with the solute in the electrolyte. Nevertheless, the solid ion conductors transport the generated cations/anions and prevent mixing with the solute, forming the pure products, thereby shortening the separation process. Xia et $a .^{33}$ developed the four-chamber solid electrocatalytic cell with a solid electrolyte to produce the proton $\left(\mathrm{H}^{+}\right)$, hydroxyl $\left(\mathrm{OH}^{-} / \mathrm{KOH}\right)$, and $\mathrm{HCOOH}$. A peak PCD of $150 \mathrm{~mA} \mathrm{~cm}^{-2}$ has been achieved at $3.36 \mathrm{~V}$ for $\mathrm{HCOOH}$ in addition to a pure $\mathrm{KOH}$ (concentration up to $0.66 \mathrm{M}$ ) with the flow of de-ionized water. The use of such water decreased the product concentration and thus necessitated the liquid electrolyte for oxidation at the anode. Gas phase reactors are not much explored owing to the presence of contaminants, which obviously depend on the cell architecture and need to be studied more. With a solid phase reactor, $\mathrm{CO}_{2} \mathrm{R}$ is performed at the high temperature from 300 to $600{ }^{\circ} \mathrm{C}$, where the cathode or anode is in an oxide form and the electrolyte is either the oxygen ion or proton conductive. The oxygen ion conductive electrolyte transports the reduced oxygen ions at the cathode to the anode to form the oxygen gas by oxidation. On the other hand, $\mathrm{CO}_{2}$ gas molecules at the cathode reduced to form hydrogen. In the proton-conductive electrolyte, the water molecules oxidized at the anode, leaving oxygen gas and protons, in which the latter flows through the proton conductive layer to the cathode reducing the $\mathrm{CO}_{2}$ molecules. Therefore, the major advantage of this reactor is the high current density at high temperature resulting from the enhanced kinetics and mass transport. At high temperature, the difficulty in sealing and $\mathrm{CO}$ as the only reduced carbon product are the key drawbacks of the solid phase reactors. Hence, it is out of the scope of this review as it ultimately focuses on $\mathrm{HCOO}^{-} / \mathrm{HCOOH}$ products.

The ER of $\mathrm{CO}_{2}$ in the liquid phase electrolyzer (Fig. 5c) is carried out in the presence of the liquid electrolyte, the gas diffusion layer (GDL) on both the anodic and the cathodic compartments and ion exchange membrane at the electrolyte bulk. Depending on the membranes (cationic, anionic, bipolar), the charges flow via the electrolyte to the anode/cathode and thereby completes the circuit. Unlike gas-phase reactors, $\mathrm{CO}_{2}$ inlet in the liquid phase does not need to be humidified; rather, it can be maintained in a pressurized mode. ${ }^{34}$ The key component of gas and liquid phase electrolyzers is the GDE (more 
discussion is available in the upcoming Section 2.3), forming gas-liquid-solid interfaces and permit $\mathrm{CO}_{2}$ to react in the gas form with the catalysts before the aqueous solutions. The GDE component fails to carry metal/foil catalysts but, fortunately, it often measures the wide variety of powder catalysts, leading to the operation of the reactors at industrial current densities. ${ }^{35}$ $\mathrm{CO}_{2}$ conversion to $\mathrm{HCOO}^{-}$using the cation exchange membranes has been studied as a function of pressure (from 10 to 50 bar), anolyte $\left(0.5 \mathrm{M} \mathrm{H}_{2} \mathrm{SO}_{4}\right)$, and catholyte $\left(1 \mathrm{M} \mathrm{KHCO}_{3}\right)$. It is found that the current density, $\mathrm{FE}$, and $\mathrm{HCOO}^{-}$concentration increase with $\mathrm{CO}_{2}$ pressure. A maximum of $\sim 90 \% \mathrm{FE}$ is observed for 40 bar but it is decreased thereafter owing to $\mathrm{HCOO}^{-}$crossover via the cation exchange membrane, and a $\mathrm{pH}$ drop due to $\mathrm{CO}_{2}$ dissolution. ${ }^{36} \mathrm{Wu}$ et al. ${ }^{37}$ discussed that the electrochemical flow cell circulating a liquid-phase electrolyte significantly enhanced the formation of $\mathrm{HCOO}^{-}$, with a $\mathrm{FE}_{\max }$ $>90 \%$ at $-1.7 \mathrm{~V} v s$. SHE and the PCD of $9 \mathrm{~mA} \mathrm{~cm}^{-2}$ while the anode is fed into $\mathrm{H}_{2}$. However, $\mathrm{FE}_{\max }$ gain is reduced to $85 \%$ at $-2.0 \mathrm{~V}$ with a PCD of $6 \mathrm{~mA} \mathrm{~cm}{ }^{-2}$. This is due to the fact that buffer circulation has enabled the conversion of formate at $\eta$ of $200 \mathrm{mV}$ even though there are gaseous or aqueous reactants at the anode. In one of the recent outstanding work done by Yasuaki Einaga group, ${ }^{38}$ the mass transport and $\mathrm{CO}_{2}$ reduction parameters are optimized with a continuous liquid fed intermittent flow cell (Fig. 6a) controlled using a synchronized dualphase double-action cylindrical pump. The cell is operated by stopping the electrolyte flow at a desired frequency and allowed a sufficient time for $\mathrm{CO}_{2}$ gas molecules to effectively reduce into $\mathrm{HCOOH}$. The synchronized cylindrical pump creates the stopstart motion (0.02 s) such that a high and a stable FE (95\%) is achieved (for BDD catalyst) in $4 \mathrm{~h}$ for $\mathrm{HCOOH}(576.98 \mathrm{mg}$ ). Further, electrochemical $\mathrm{CO}_{2}$ reduction is conducted with and without air chambers to counter and minimize the pressure lost when the pump stops the electrolyte flow. When the air chamber flow is regular as in the continuous flow system, the FE decreased $<10 \%$ after $2 \mathrm{~h}$. This conveys that controlling the stop-start motion of the electrolyte (Fig. 6b) flow is also a crucial factor behind the $\mathrm{HCOOH}$ production. Moreover, the observed result is 10 times higher than the conventional flow cell system $^{39}$ and this type of $\mathrm{CO}_{2}$ electrolyzer system seek industrial-scale applications. The discrepancy between liquid and gas phase electrolyzers is the introduction of a liquid electrolyte layer among the cathode and the ion exchange membrane. Besides, the production of $\mathrm{HCOOH}$ by these electrolyzers showed notable differences if GDEs are used. When switching from the liquid-phase electrolysis to the gas-phase, $\mathrm{CO}_{2} \mathrm{R}$ for $\mathrm{HCOO}^{-}$has been promoted and the figures of merits are increased such as the average overpotential ( 0.91 to $1.09 \mathrm{~V}$ ), the average $\mathrm{FE}$ ( 40.5 to $50.6 \%$ ), and the average current density (9.2 to $28.2 \mathrm{~mA} \mathrm{~cm}{ }^{-2}$ ). ${ }^{32}$ It is also important to notify the challenges in the flow cells such as the crystallization of salts by GDL, high ohmic losses due to the aqueous electrolytes, the water management issues, and sensitivity to contaminants. At the gas-liquid-solid three-phase interfaces in GDE, the carbonate/bicarbonate salts have lower solubility assigned to the reaction of $\mathrm{CO}_{2}$ with the alkaline electrolyte, which makes the GDE more hydrophilic and flooded over time. ${ }^{40}$ In addition, the absorption of $\mathrm{CO}_{2}$ into the alkaline catholyte leads to carbonates, which influences the system stability and increases the capital costs. These discussions show that it is necessary to jump from the liquid-phase to the gas-phase systems as they have the ability to raise the current densities well above the base level of the techno-economic analysis. However, a further analysis would be required, though the economic feasibility parameters of liquid and gas phase processes are dissimilar.

\subsection{Gas diffusion electrode (GDE)}

Fortunately, the mass transport limitation from two zone reactors could be sorted out by the three zone gas diffusion electrodes (Fig. 7), which operate the catalysts in the powder form on gas diffusion layers (GDL). $\mathrm{CO}_{2}$ is supplied to the catalyst by diffusion through the GDL in contact with the electrolyte flow. $\mathrm{CO}_{2} \mathrm{R}$ commences at the gas and the liquid electrolyte interface thereby enhances the reaction kinetics, causing efficient mass transport. In $\mathrm{H}$-type cells, $\mathrm{CO}_{2}$ is to be saturated with the bulk electrolyte. When $\mathrm{CO}_{2} \mathrm{R}$ happens, the entire products move
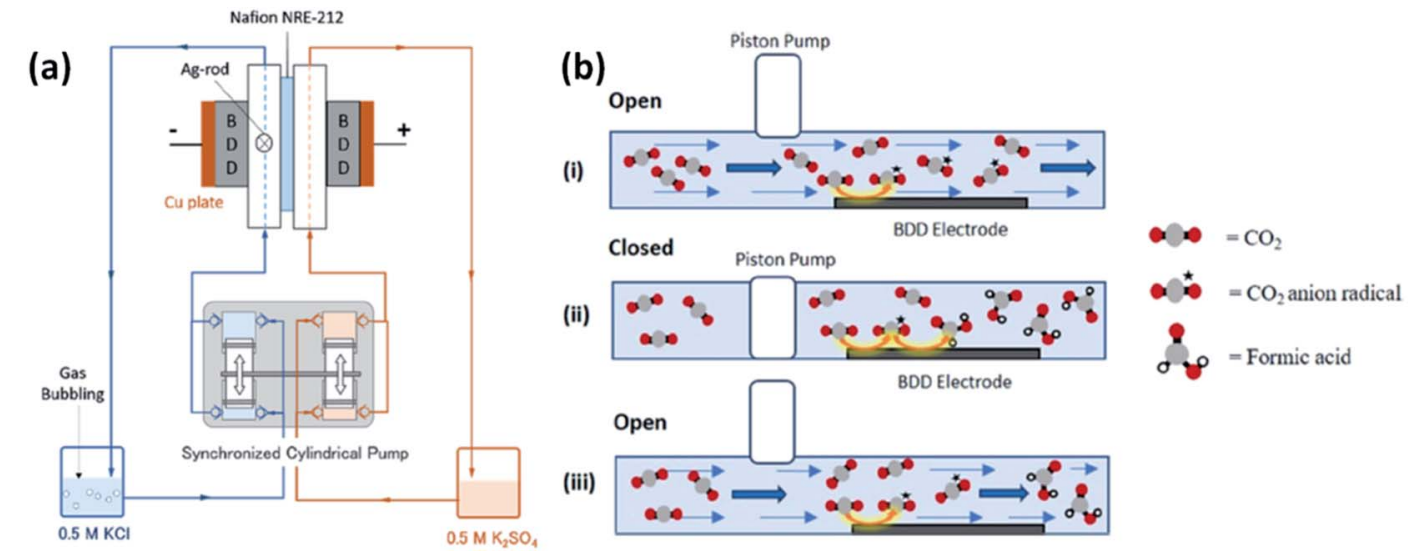

Fig. 6 (a) Pictorial representation of the intermittent flow cell and (b) demonstration of the stop-start motion on the flow conditions (i) before the piston pump closes the pipe (as in the continuous cell), (ii) when the piston pump closes the pipe, and (iii) after the piston pump opens the pipe [ref. 38, Copyright (c) 2021, American Chemical Society]. 


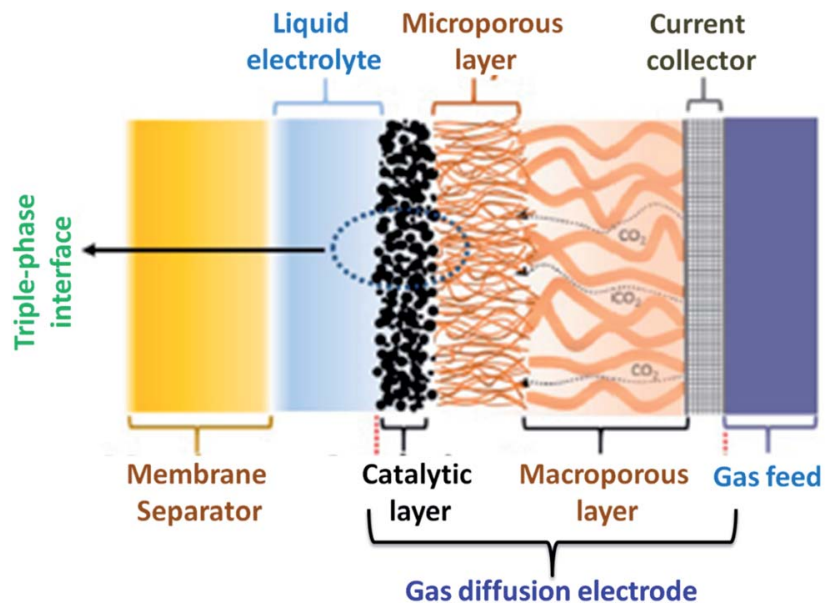

Fig. 7 Schematic of a gas diffusion electrode (GDE) with the membrane separator in the liquid phase $\mathrm{CO}_{2}$ electrolyzer showing three-phase interfaces as the liquid electrolyte, catalytic layer and the $\mathrm{CO}_{2}$ gas molecules [ref. 9, Copyright $\odot$ 2020, Elsevier Ltd].

from the surface in the opposite direction to the incoming $\mathrm{CO}_{2}$. In contrast, GDE with GDL carries the liquid products in the aqueous state because of the hydrophilicity and the gas products migrate from the gas side. The advantage of using GDE over H-type cells, GDL is linked to the good mass transfer characteristics and the short diffusion length. It is understood that the diffusion path is $50 \mu \mathrm{m}$ for dissolved $\mathrm{CO}_{2}$ from the bulk to the non-permeable catalyst, whereas from gaseous $\mathrm{CO}_{2}$ to the liquid surrounded catalyst is at the level of only about $50 \mathrm{~nm} .{ }^{\mathbf{4 1 , 4 2}}$ This shorter diffusion path length enables the $\mathrm{CO}_{2}$-saturated electrolyte layer on the catalyst, preventing the hydrogen evolution reaction. ${ }^{42}$

Further, $\mathrm{CO}_{2}$ gas approaches the active sites faster before it reacts with $\mathrm{OH}^{-}$ions in the electrolyte, enabling the use of alkaline electrolytes. Another distinct feature of GDL is the reaction direction of $\mathrm{CO}_{2}$, whereas in the case of $\mathrm{H}$-cells, it approaches the catalyst surface from the bulk. Meanwhile, in GDL, the reactant $\mathrm{CO}_{2}$ gas is purged via the hydrophobic layer, which lacks the agglomeration of gaseous products and blocks the catalyst surface, facilitating the adsorption of $\mathrm{CO}_{2}$ molecules. Thus, the use of GDL simultaneously overcomes the challenges of mass transfer and the availability of $\mathrm{CO}_{2}$ at the liquid/catalyst interface, resulting in a significant activity and lower cell potential so that GDE-based electrolyzers have a great potential for scaling up the devices. However, under this circumstance, it is prone to show product crossflow via the GDL due to the pressure difference and $\mathrm{CO}_{2}$ bubbles in the catholyte leads to a fluctuation in the cell voltage upon time. ${ }^{43}$

In this configuration, extensive studies have been proven to be efficient over conventional $\mathrm{H}$-type cells. For example, $\mathrm{Bi}_{2} \mathrm{O}_{3}$ nanotube catalyst showed $100 \%$ selectivity at $-1.05 \mathrm{~V} v$ s. RHE, a high current density ( $60 \mathrm{~mA} \mathrm{~cm}_{\text {geo }}{ }^{-2}$ ), and a long-term catalytic stability $>48 \mathrm{~h}$ in $0.5 \mathrm{M} \mathrm{KHCO}_{3}$ under a standard H-type cell. ${ }^{44}$ When the reactor is subjected to GDL, the nanotubederived Bi delivered a larger current density of $288 \mathrm{~mA} \mathrm{~cm}$
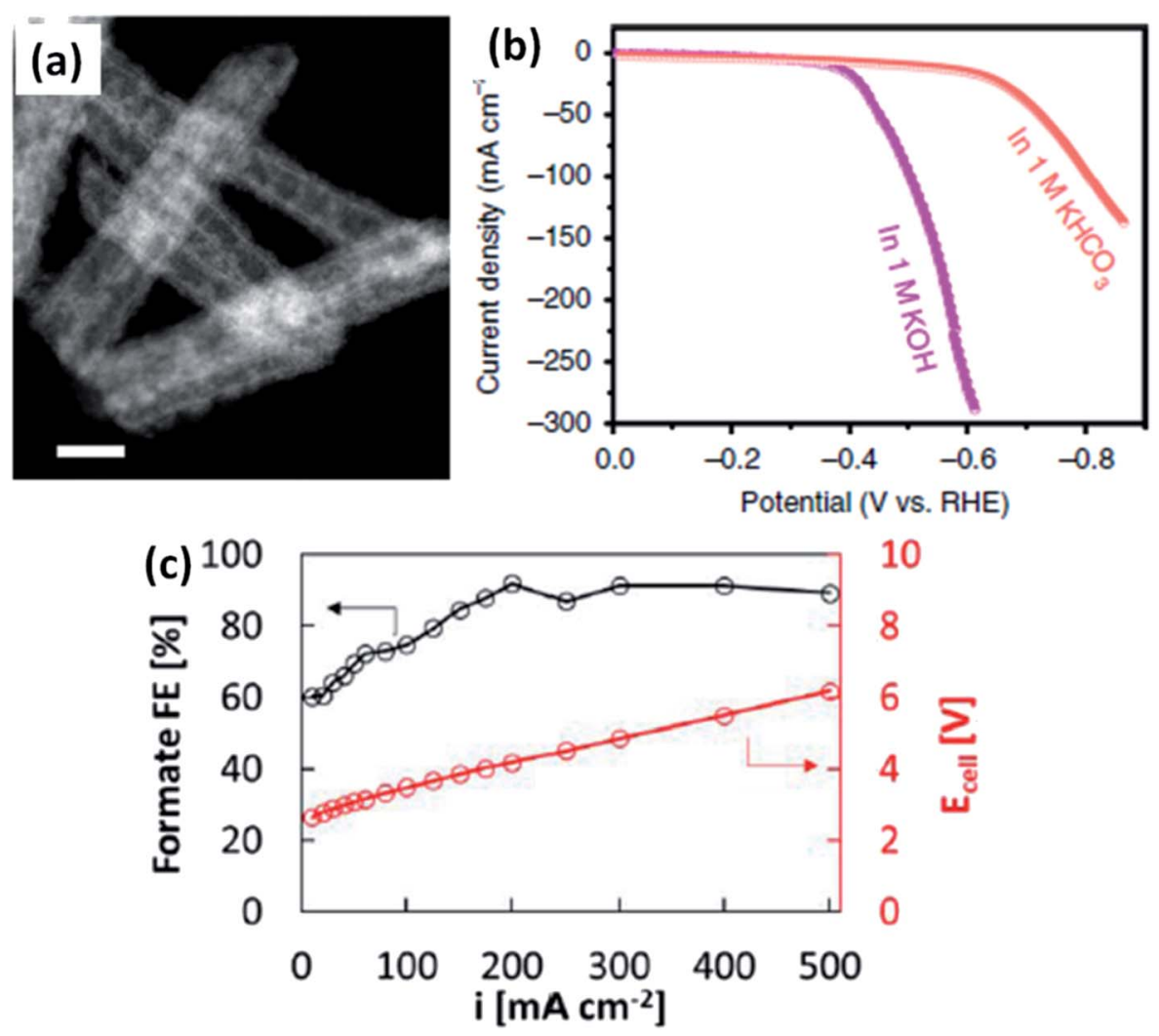

Fig. 8 (a) STEM-HAADF images of $\mathrm{Bi}_{2} \mathrm{O}_{3}$ nanotubes, (b) polarization profiles of nanotube-derived $\mathrm{Bi}$ in $1 \mathrm{M} \mathrm{KHCO}$ and $\mathrm{KOH}$ [ref. 44 , $\mathrm{Copyright}(\mathrm{C}$ 2019, Springer Nature] and (c) the formate FE and polarization curve [ref. 45, Copyright (c 2020, American Chemical Society]. 


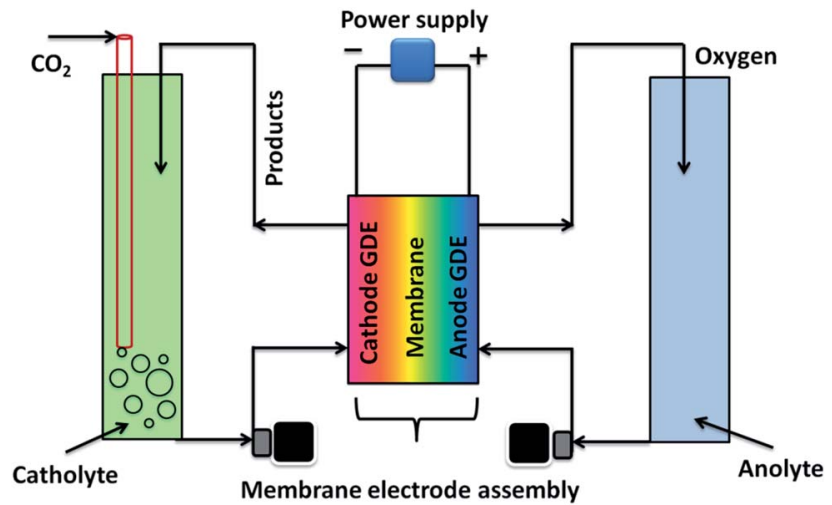

Fig. 9 Membrane electrode assembly with GDE [reproduced from ref. 25, Copyright @ 2016 Elsevier].

for $-0.61 \mathrm{~V}$ in $1 \mathrm{M} \mathrm{KOH}$ (Fig. 8a and b). In the other study, ${ }^{45}$ $\mathrm{CO}_{2} \mathrm{R}$ to $\mathrm{HCOO}^{-}$at the gas diffusion electrode $\left(25 \mathrm{~cm}^{2}\right)$ with a carbon-supported $\mathrm{SnO}_{2}$ electrocatalyst produced $90 \% \mathrm{FE}$ at $500 \mathrm{~mA} \mathrm{~cm}^{-2}$ while retaining a total cell voltage $\leq 6 \mathrm{~V}$, as shown in Fig. 8c. Besides the several improvements, GDL undergoes the crystallization of the hydroxide and bicarbonates salts on the porous layer because of the richness of the hydroxide ions at the cathode. Moreover, the local $\mathrm{pH}$ increases $\geq 12$ for the current densities more than $50 \mathrm{~mA} \mathrm{~cm}{ }^{-2}$, leading to a different local environment for $\mathrm{CO}_{2} \mathrm{R}$ to occur. In the context of the operation conditions, the higher current gives rise to a notable ohmic loss $i R \mathrm{~s}$ and then the $\mathrm{pH}$ of the electrolyte, temperature of the electrodes, and the charge conductivity are varied over time due to the concentration polarization between the electrodes. Due to the hydrophobic nature of the GDL nanostructure, the contaminants in the electrolyte are harmful to the active sites at the catalyst surface. In order to resolve these ambiguities, Dinh et al. ${ }^{46}$ framed a robust configuration, where the electrocatalyst was sputter-coated on a porous layer of PTFE and the nanoparticle carbon is spray-deposited, thereby stabilizing the copper catalytic layer in $\mathrm{KOH}$ solution. Such an architecture is extended to the $\mathrm{CO}_{2}$ gas diffusion zone with the catalyst surface and thus promoted more $\mathrm{CO}_{2}$ conversion and higher current density. Wang's group ${ }^{33}$ reported that the continuous $\mathrm{CO}_{2} \mathrm{R}$ utilizing solid electrolytes generated cations $\left(\mathrm{H}^{+}\right)$and anions $\left(\mathrm{HCOO}^{-}\right)$that combined to form pure $\mathrm{HCOOH}$ solution. With the $\mathrm{Bi}$ catalyst, the cathode produced a pure $\mathrm{HCOOH}$ concentration up to $12 \mathrm{M}$ (FE > 90\%) and a stable generation of $0.1 \mathrm{M} \mathrm{HCOOH}$ for $100 \mathrm{~h}$; besides, a negligible degradation is seen in selectivity and activity. Further, in an interesting research article by Delafontaine et al. ${ }^{47}$ the concentration of $\mathrm{CO}_{2}$ molecules in aqueous solution with $\mathrm{H}$ type electrolyzer is found to be $0.038 \mathrm{M}$ and the corresponding diffusion coefficient is $0.0016 \mathrm{~mm}^{2} \mathrm{~s}^{-1}$ in $\mathrm{CO}_{2}$-saturated $0.1 \mathrm{M} \mathrm{KHCO}_{3}$. When the humidified $\mathrm{CO}_{2}$ is supplied to the flow cell with GDE, the concentration of $\mathrm{CO}_{2}$ is increased up to $0.041 \mathrm{M}$ and 10000 -fold enriched diffusion coefficient $\left(16 \mathrm{~mm}^{2}\right.$ $\mathrm{s}^{-1}$ ) is obtained. A more gaseous $\mathrm{CO}_{2}$ has been reached the catalyst, resulting in a large $\mathrm{CO}_{2}$ availability and a consequent raise in the $\mathrm{CO}_{2} \mathrm{R}$ PCD. ${ }^{24,47}$ Therefore, the usage of GDEs is the prominent strategy to increase the $\mathrm{HCOO}^{-} \mathrm{PCD}$ but it is very much challenging to avail a quick $\mathrm{HCOO}^{-}$production rate and a low overpotential with a high $\mathrm{FE}_{\mathrm{HCOOH}}$.

\subsection{Membrane electrode assembly (MEA)}

To overcome the drawbacks in the H-type cell, gas and liquid phase flow reactors equipped MEA have been developed, in which the cathodic layer of GDE has made direct contact with the polymer electrolyte membrane (PEM) in a zero-gap configuration (Fig. 9). MEA recovers from the ohmic losses and the contamination of the cathode catalyst in the catholyte by the removal of the catholyte between the membrane and GDE, which brings it higher efficiency and stability. Thus, MEA consists of an anode compartment with a liquid anolyte and the cathode chamber with only a gas phase. Therefore, water management on the cathode catalyst surface became one of the major problems in MEA. By giving humidified $\mathrm{CO}_{2}$ as the feed, the above problem can be solved but still the membrane turned dry even under humidification; hence, the anolyte is necessitated to supply water on the cathode catalyst. Since MEA does not enclose the reference electrode, $\mathrm{CO}_{2} \mathrm{R}$ is performed at the cell voltage or the current compared to the working electrode potential. However, CO is a targeted product in MEA reactors and a remarkable current density of $0.5 \mathrm{~A} \mathrm{~cm}^{-2}$ with more than $85 \%$ of $\mathrm{FE}$ was achieved. ${ }^{48}$ However, $\mathrm{CO}_{2} \mathrm{R}$ on the liquid
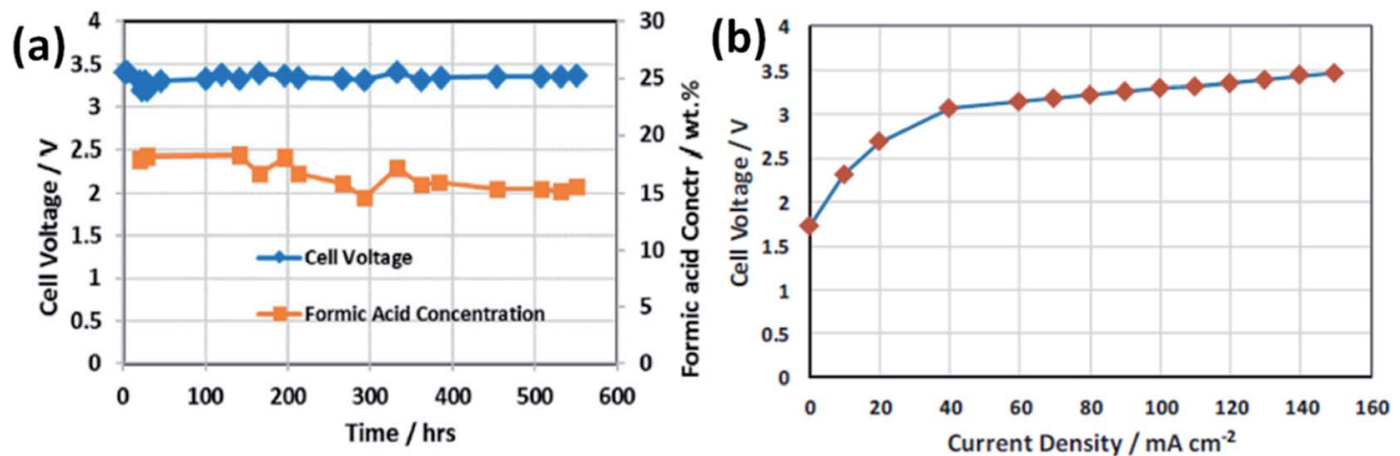

Fig. 10 (a) Formic acid cell performance using graphite flow field, nanoparticle Sn@GDE, Nafion® 212 membrane, and IrO 2 coated GDE and (b) cell voltage polarization plot [ref. 50, Copyrights @ 2017 Elsevier Ltd]. 
products such as alcohols are scarce due to MEA swelling, affecting the durability too. But, fortunately, MEAs are capable of generating high purity products; in particular, $\mathrm{HCOO}^{-}$ production has been vigorously studied. ${ }^{49}$ Lee et $a l .{ }^{32}$ investigated the catholyte-free $\mathrm{CO}_{2} \mathrm{R}$ to avoid the solubility limitation by commercial Sn nanoparticles as the cathode catalyst. Despite a decrease in $\mathrm{CO}_{2}$ solubility, the PCD of $\mathrm{HCOO}^{-}$enhanced two times with $52.9 \mathrm{~mA} \mathrm{~cm} \mathrm{~cm}^{-2}$ when the reaction temperature increased from 303 to $363 \mathrm{~K}$. Also, an appreciably high $\mathrm{HCOO}^{-}$ concentration of $41.5 \mathrm{~g} \mathrm{~L}^{-1}$ has been observed with a significant PCD (51.7 $\left.\mathrm{mA} \mathrm{cm}^{-2}\right)$ and high FE (93.3\%) at 2.2 V. An improved electrochemical reduction is demonstrated (Fig. 10a and b) for Sustainion $^{\mathrm{TM}}$ anion exchange membrane with a nanoparticle $\mathrm{Sn}$ GDE carrying an imidazole ionomer, which displayed a stable electrochemical cell performance for $500 \mathrm{~h}$ at $140 \mathrm{~mA} \mathrm{~cm}^{-2}$ and at a cell voltage of only $3.5 \mathrm{~V}^{.0}$ More recently, Thijs et al. ${ }^{51}$ adopted a novel strategy to enhance the $\mathrm{CO}_{2} \mathrm{R}$ to $\mathrm{HCOO}^{-}$or $\mathrm{HCOOH}$ by the recirculation of the by-products to the reactor along with unconverted $\mathrm{CO}_{2}$. It has been elaborated that different MEA-type gas and liquid phase reactors (Fig. 11a) have garnered a predominant role in the electrochemical reduction of $\mathrm{CO}_{2}$ to $\mathrm{HCOO}^{-}$or $\mathrm{HCOOH}$. With the gas phase reactor using type I configuration, $\mathrm{FE}$ toward $\mathrm{HCOOH}$ is limited in the range from 5 to $12.5 \%$ while the $\mathrm{H}_{2}$ product is predominant when $\mathrm{H}_{2}$ is employed as the source of protons at the anode to the cathode via the Nafion membrane. ${ }^{52}$ In another study, the alkaline anion exchange membrane displayed promoted selectivity for $\mathrm{CO}_{2} \mathrm{R}$ in contrast to the acidic proton exchange membrane owing to the inaccessibility of the protons. Such type of MEA-based reactors are adopted for $\mathrm{CO}$ rather than $\mathrm{HCOO}^{-}$or $\mathrm{HCOOH}$ and because the $\mathrm{HCOO}^{-}$crossover to anode is a serious issue and more $\mathrm{HCOOH}$ acidification is required to maintain the proton balance. ${ }^{50,53}$ Therefore, a center flow compartment was integrated to the MEA, which drives the water liquid flow between the anodic proton exchange membrane and the cathodic anion exchange membrane to acidify the $\mathrm{HCOO}^{-}$and discard the
$\mathrm{HCOOH}$ from the reactor (type II).$^{50}$ On the other hand, the type III configuration studied by Park's group ${ }^{32}$ showed FE against $\mathrm{HCOO}^{-}$up to $93 \%$ with liquid $\mathrm{KOH}$ as the anolyte, highly humidified $\mathrm{CO}_{2}$, and increased temperature. Further, type $\mathrm{IV}^{54}$ is developed for the entire gas phase $\mathrm{CO}_{2} \mathrm{R}$ where MEA consists of an alkaline ionomer layer at the cathode, attached with a membrane, and separates the anode from the cathode. This configuration demonstrates excellent results; however, it would be further explored for $\mathrm{HCOO}^{-}$or $\mathrm{HCOOH}$. Among these four configurations, $\mathrm{H}_{2}$ evolves as the main by-products and the aqueous environment is needed for the proton source against $\mathrm{HCOOH}$ formation. In order to avoid the formation of $\mathrm{H}_{2}$ byproduct, a new strategy has been developed by Thijs et al. ${ }^{51}$ based on type III configuration. A typical gas phase $\mathrm{CO}_{2} \mathrm{R}$ reactor with recirculation has been proposed in Fig. 11b and herein, water vapour is supplied. The created protons due to the water oxidation transport via the membrane from the anode to the cathode and further the water at the cathode is originated by an electro-osmotic drag. The cathodic compartment composes by-products such as $\mathrm{HCOOH}, \mathrm{H}_{2} \mathrm{O}$, unconverted $\mathrm{CO}_{2}, \mathrm{H}_{2}, \mathrm{CO}$, and some higher order products. Therefore, the cathode outlet gas stream has been directed to the condenser wherein $\mathrm{HCOOH}$ and $\mathrm{H}_{2} \mathrm{O}$ are discharged by condensation. Unconverted $\mathrm{CO}_{2}$ and by-products are re-circulated to the cathode and amalgamated with the $\mathrm{CO}_{2}$ inlet. At the end, the pressure is tuned by a valve $\mathrm{P}$, evacuating the unconverted $\mathrm{CO}_{2}$ and by-products to keep away from excessive build up. For the initial accumulation of the byproducts $\left(\mathrm{H}_{2}\right)$, the electrochemical formation potential of the undesired by-products in the reactor is moved to higher values and favored the formation of $\mathrm{HCOOH}$, for which the potential is unaffected. Besides, mathematical simulation has found that the re-circulation of the by-products necessitated substantially enhanced $\mathrm{HCOO}^{-}$selectivity at low pressure. Further, experimental validation with an MEA reactor validated as the decrease in the $\mathrm{H}_{2}$ selectivity for Sn-nanoparticle on the carbon cathode is about $40 \%$ (in gas mixtures $0.07 \mathrm{MPa}$ of $\mathrm{H}_{2}$ and $0.03 \mathrm{MPa}$ of

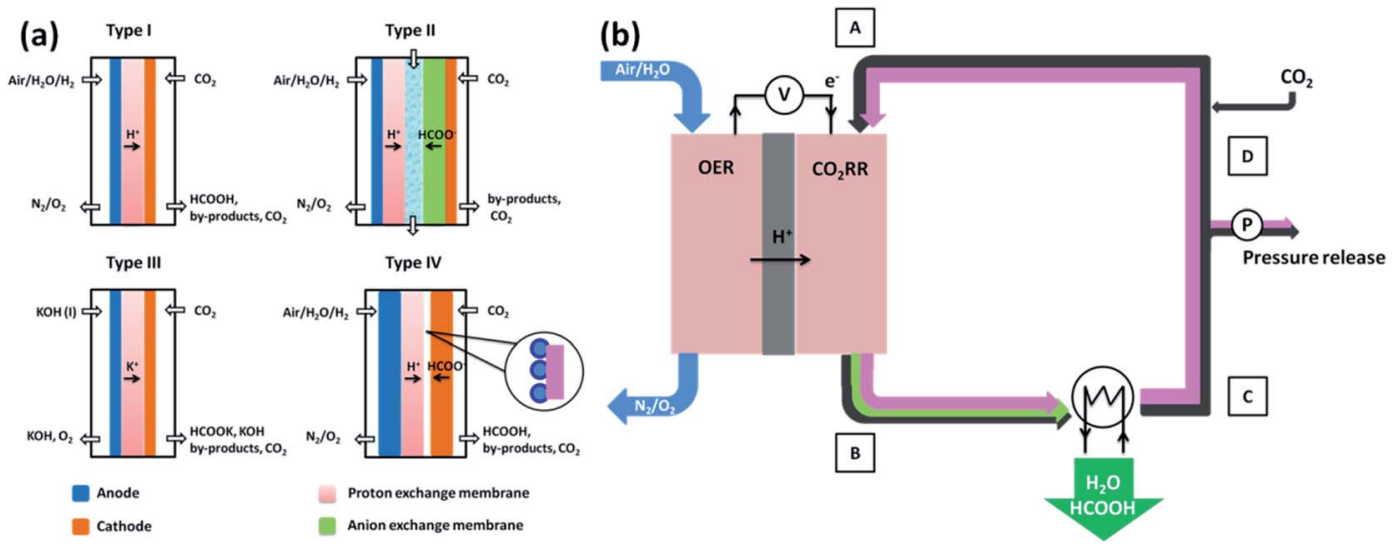

Fig. 11 (a) MEA-type reactor configurations for $\mathrm{CO}_{2} \mathrm{R}$. Type I and IV operated in the vapor phase, type II carries a water liquid flow in the center compartment and type III holds a liquid anolyte flow. (b) MEA based gas phase $\mathrm{CO}_{2} \mathrm{R}$ reactor with the recirculation of by-products and maximized $\mathrm{HCOOH}$ production. The effect of recirculation on the reaction selectivity has been simulated by calculating the variation of partial pressures of the gases at four steps. At the inlet (A) and outlet (B), at the outlet of a condenser differentiating $\mathrm{HCOOH}$ and $\mathrm{H}_{2} \mathrm{O}$ from the gas stream (C), and behind a pressure valve (P) allowing a part of the gas (D) [reproduced from ref. 51, no permission is required]. 


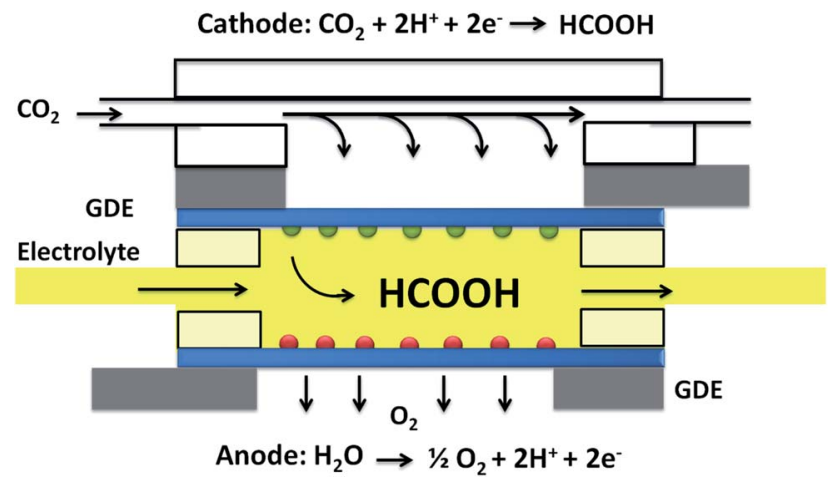

Fig. 12 Microfluidic reactor setup [reproduced from ref. 25, Copyright (c) 2016 Elsevier]

$\mathrm{CO}_{2}$ ) as opposed to pure $\mathrm{CO}_{2}$. This has led to a notable increase in the $\mathrm{HCOO}^{-}$selectivity and energy efficiency. In conclusion, $\mathrm{CO}_{2} \mathrm{R}$ from the MEA-based reactor excels in the view point of lowered material costs, reduced cell potential promoted $\mathrm{CO}_{2}$ mass transfer, and selectivity. Water management at the cathode, liquid product collection difficulty, and crossover of liquid products are the challenges in the MEA setup. To better understand, more investigations will be needed on the mechanism of electrocatalytic reactions, catalyst, and the ionexchange interface for the selective formation of products. ${ }^{55}$

\subsection{Microfluidic reactor}

Kenis' group ${ }^{56}$ proposed the microfluidic reactor (MR), also called the microfluidic flow reactor (Fig. 12), where the liquid electrolyte stream separating the anodes and the cathodes is passed through a thin channel $(<1 \mathrm{~mm})$ in a laminar flow instead of an ion exchange membrane (membrane less configuration). The product formation in MR happens with the redox reaction via diffusion rather than by the membrane. This excludes the challenges associated with mass transfer and neutralization by the alkaline anolyte and acidic catholyte attributed to the crossover. As a consequence, it reduces the concentration of the $\mathrm{OH}^{-}$and $\mathrm{H}^{+}$ions for the enrichment of the current density. The uniqueness of the membraneless configuration enables the compositional tunability of the electrolytes unlike membrane-based $\mathrm{CO}_{2} \mathrm{R}$ reactors (one of the electrodes is in an acidic environment and other is in an alkaline environment). This results in the optimization of the kinetics and thermodynamics at both the electrodes, thereby enhancing the overall performance of the cell. To increase the current density, MR with GDE contains a very thin diffusion layer $(50 \mathrm{~nm})$ composed of three components such as a cathodic layer, GDL, and a gas flow field. Its porous structure gives rise to the physical support and the gas transport tunnels to the cathodic layer. Moreover, the hydrophobic property of GDL is treated by hydrophobic additives such as polytetrafluoroethylene, which safeguards the blocking of the pores while facilitating the $\mathrm{CO}_{2} \mathrm{R}$ transport to the cathodic layer. Although a high current density more than $400 \mathrm{~mA} \mathrm{~cm} \mathrm{~cm}^{-2}$ can be achieved by MR, it undergoes product crossover and re-oxidation (cathodic products to the anode and the reduction of oxygen to the cathode), thus decreasing the productivity and efficiency. In this regard, an attempt has been made with a dual electrolyte system to produce $\mathrm{HCOOH}$ under the optimized anolyte and catholyte $\mathrm{pH}$ conditions. ${ }^{57}$ The current density has been increased from 10 to
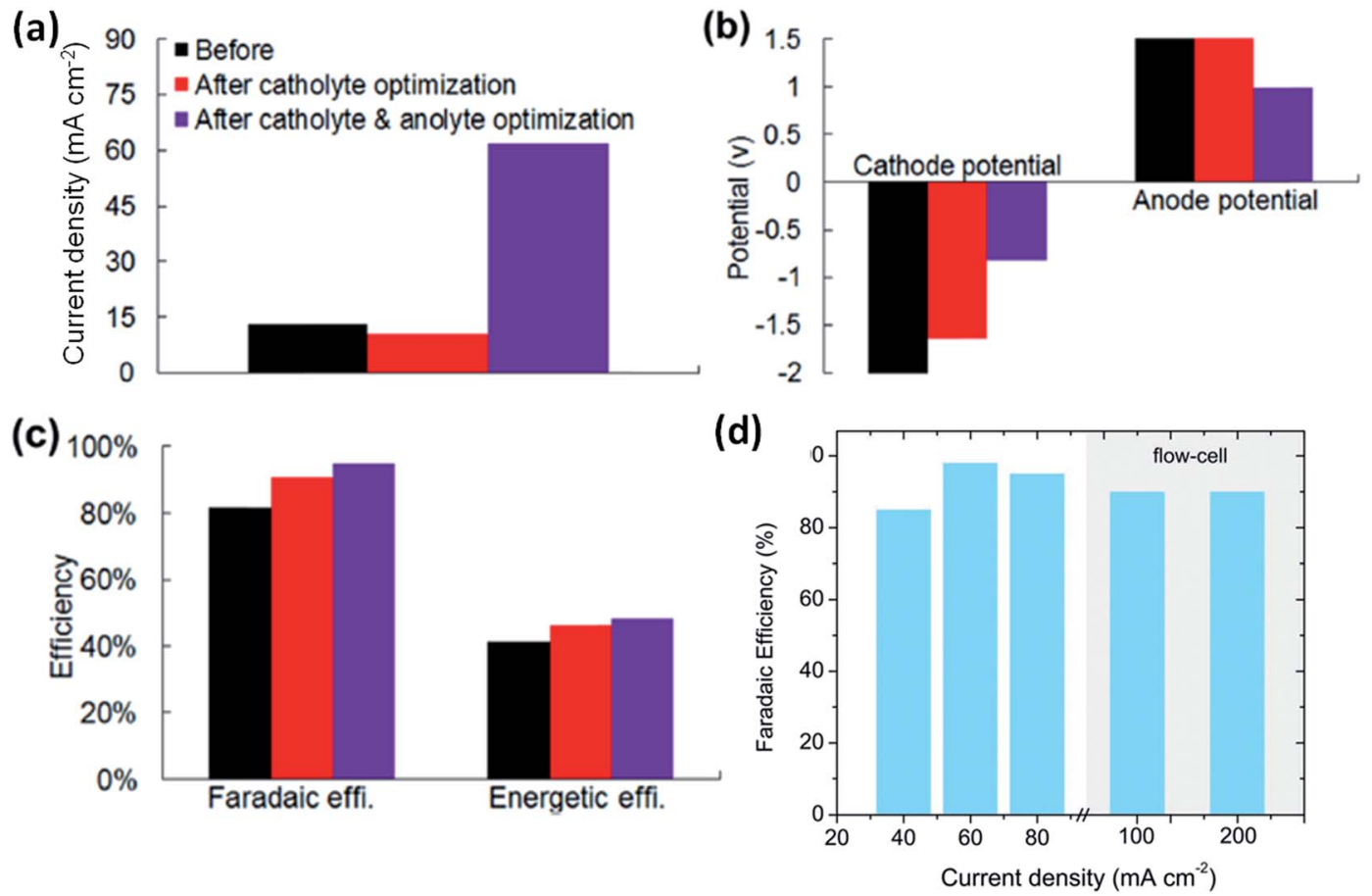

Fig. 13 (a) Current density at $2.8 \mathrm{~V}$, (b) cathode potential at $100 \mathrm{~mA} \mathrm{~cm}^{-2}$ under catholyte $\mathrm{pH}$ of 7, 1 and 0 ; anode potentials at $150 \mathrm{~mA} \mathrm{~cm}^{-2}$ under anolyte $\mathrm{pH}$ of 7, 13 and 14, (c) peak faradaic and energy efficiencies before and after electrolyte optimization [ref. 57 Copyright (C) 2016 Elsevier] and (d) FE of $90 \%$ up to $200 \mathrm{~mA} \mathrm{~cm}^{-2}$ for BiOBr deposited on the GDE carbon electrode [ref. 58 Copyright @ 2018 Wiley]. 
$60 \mathrm{~mA} \mathrm{~cm}^{-2}$ at $2.8 \mathrm{~V}$ (Fig. 13a-c) upon anolyte optimization (pH $=14$ ) along with FE (81.6 to $95.6 \%$ ) and the peak energy efficiency (41.7 to $48.5 \%$ ). Further, Whipple et al. ${ }^{56}$ reported efficient $\mathrm{CO}_{2} \mathrm{R}$ to $\mathrm{HCOOH}$ using Sn-coated GDE ( $\mathrm{pH}$ values from 4$10)$, which worked as an effective MR with a notable FE (89\%), energy efficiency (45\%), and PCD $\left(100 \mathrm{~mA} \mathrm{~cm}^{-2}\right)$ at $\mathrm{pH}=4$. At lower $\mathrm{pH}$, Sn dissolved in a highly acidic medium. It is worthwhile to mention that the comparative study between the H-type electrolyzer and MR has been demonstrated on BiOBrdeposited GDE carbon electrode. ${ }^{58}$ Even though the H-type liquid electrochemical cell had a mass transport limitation, it delivered a current density of $80 \mathrm{~mA} \mathrm{~cm}^{-2}$ and stable operation for $65 \mathrm{~h}$ toward $\mathrm{HCOO}^{-}$.

On the other hand, it further shows a high $\mathrm{HCOO}^{-}$selectivity (over 90\%) with a PCD (200 $\mathrm{mA} \mathrm{cm} \mathrm{cm}^{-2}$ ) for MR configuration (Fig. 13d). This comparison dictates that the gas phase MR reactors have the potential for high productivity compared to the liquid phase electrolyzers. Castillo et al. ${ }^{59}$ investigated the influence of Sn catalyst loading and size on carbon paper and superior performance was identified for the loading (0.1$0.75 \mathrm{mg} \mathrm{cm}^{-2}$ ), smallest particle size (150 nm), FE (70\%), and the current density $\left(90 \mathrm{~mA} \mathrm{~cm}{ }^{-2}\right)$. These investigations show that the advantages and importance of MR may eventually find large-scale applications.

\subsection{Zero-gap electrolyzer}

In the direction of large-scale applications, the zero-gap electrolyzer has newly emerged and the absence of a cathode flow channel results in a difference when compared to the flow reactor. This enables the conversion of $\mathrm{CO}_{2}$ into desired products even without the liquid catholyte and its circulation loop is also not needed, resulting in a very low cell resistance. This configuration not only affords reduced ohmic losses but also attenuates the problems associated with poor membrane hydration and electrode flooding at higher current densities. Further, this could minimize any losses attributed to the dissolution of $\mathrm{CO}_{2}$ in the catholyte, which in turn decreases the power required to produce the same quantity of $\mathrm{CO}$ by $50 \%$ with a similar electrocatalyst as in the flow cell. In this context, the zero-gap electrolyzer is the promising configuration for $\mathrm{CO}_{2} \mathrm{R}$ to value-added products in the future. Fig. 14 shows two types of zero-gap electrolyzers based on the parallel and the interdigitated flow field patterns, and their electrochemical $\mathrm{CO}_{2} \mathrm{R}$ performances are compared with a well-known catholyte flow by the electrolyzer studied by Mot et al. ${ }^{60}$ For the $\mathrm{CO}_{2}$ flow rate (200

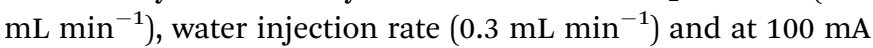
$\mathrm{cm}^{-2}$ for $1 \mathrm{~h}$, the $\mathrm{FE}$ of $\mathrm{HCOO}^{-}, \mathrm{H}_{2}$, and $\mathrm{CO}$ against the cathode flow by parallel and interdigitated patterns are obtained to be 67,43 , and $81 \%$, respectively. Unfortunately, the parallel pattern zero-gap electrolyzer is less efficient than the catholyte flow but the interdigitated pattern zero-gap electrolyzer has shown better performance than the former. Because the interdigitated flow field patterns have forced the $\mathrm{CO}_{2}$ into GDE, hence, efficient mass transfer occurred toward the catalyst surface as a result of diffusion and convection. Furthermore, the rich water availability at GDE provides more humidification of the MEA. ${ }^{60}$ Recently, the $\mathrm{CO}_{2} \mathrm{R}$ to $\mathrm{HCOO}^{-}$was investigated by the gas-fed zero-gap and $\mathrm{H}$-type electrolyzers in alkaline and almost basic electrolytes. It is found that the FE and PCD at $-1.87 \mathrm{~V}$ are prominent as $20.1 \%$ and $148 \mathrm{~mA} \mathrm{~cm}^{-2}$, respectively, when the hydroxide solution is used in the gas-fed zero-gap electrolyzers. Conversely, the H-type cell generated an FE of $2.6 \%$ and a PCD of $7.5 \mathrm{~mA} \mathrm{~cm}^{-2}$ for the optimized potential. This observation underpins that the knowledge garnered by batch type experiments does not lead to practical approaches aimed at industrial $\mathrm{CO}_{2} \mathrm{R}$. Therefore, many more experiments should be done beyond the catalyst development-oriented approach such as rational electrolyzer design, engineering, and process optimization to pave strong and stable gas-liquid
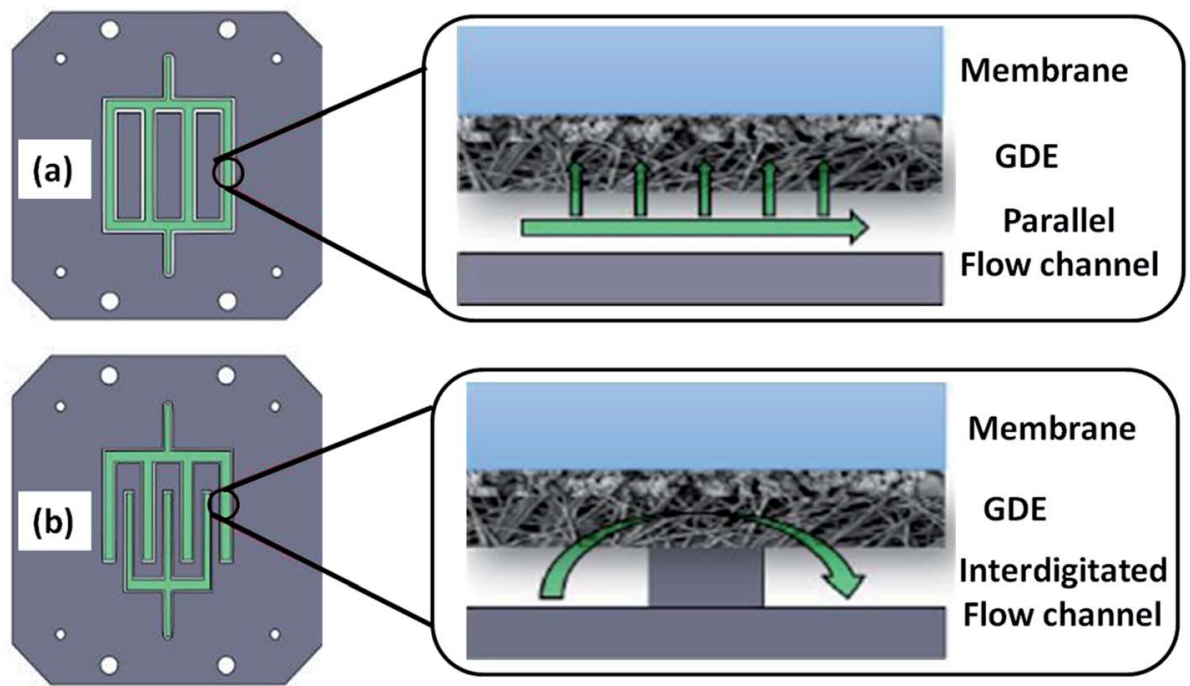

Fig. 14 Schematic representation of the two types of zero-gap electrolyzers with (a) the parallel flow field patterns (mass transfer due to diffusion) and (b) the interdigitated patterns (mass transfer due to both diffusion and convection) [ref. 60, Copyright (c) 2020, Wiley-VCH]. 
interfaces for achieving high current density and durability toward large-scale applications.

Besides, Table 2 demonstrates the figures of merit (potential, current density, and $\mathrm{FE}$ ) of $\mathrm{HCOOH} / \mathrm{HCOO}^{-}$by the $\mathrm{CO}_{2} \mathrm{R}$ process for different reactor designs. Based on the above discussions, it is understood that the engineering of the reactor design for $\mathrm{CO}_{2}$ electrochemical reduction to formic acid has gained tremendous attention in the past few decades for fuel cell and energy storage applications. Nevertheless, the practical application is hampered by several limitations as elucidated in this perspective; hence, the $\mathrm{CO}_{2} \mathrm{R}$ is still being processed at the laboratory scale. Currently, $\mathrm{H}$-type cells are commercialized despite their limitations in $\mathrm{CO}_{2}$ solubility and mass transport, causing low energy efficiency. However, the flow type reactor could be a potential candidate in the future to attain the base line current density and long-term stability for industrial applications. The prime motivation of the review is to bring readers' attention toward the construction of economic, scalable, and energy-efficient $\mathrm{CO}_{2} \mathrm{R}$ electrolyzers to produce valueadded formic acid. MEA-based and MR configurations the enhanced energy efficiency due to the zero-gap mode and membraneless diffusion mechanism, respectively, lacking the ohmic losses and facilitating the mass transport. In particular, MEA-based reactors lead to the pure form of the liquid products, enabling the choice for future large-scale applications.

\section{Membrane separator}

The membrane is one of the crucial parts of electrochemical reactors, which contributes a crucial role in the current density and $\mathrm{FE}$ of the $\mathrm{CO}_{2} \mathrm{R}$ process by preventing product crossover between the electrodes. Ion exchange membranes are often employed due to their selectively permeable characteristic for desired type of ions while holding other ions or neutral molecules. There are three different types, such as monopolar exchange membranes (cation exchange membrane and anion exchange membrane) and the bipolar membrane (BPM) as both the cationic and anionic exchangeable characteristics. ${ }^{77-79}$ This governs the ion transport pathway between the anode and cathode depending on the $\mathrm{pH}$ of the reaction environment, thereby affecting the kinetics of the $\mathrm{CO}_{2} \mathrm{R}$ reactions. The current perspective in the upcoming sections discusses the conductivity issues and challenges on $\mathrm{CO}_{2} \mathrm{R}$ parameters (faradaic efficiency and current density) with the introduction of different ionic exchange membranes for $\mathrm{HCOOH} / \mathrm{HCOO}^{-}$production.

\subsection{Cation exchange membrane}

The cation exchange membrane, also known as the proton exchange membrane (PEM), permits the transit of cations while keeping the anions and has potential applications in water electrolyzers and fuel cells. A well-studied PEM consists of the perfluorosulfonic acid derivatives with sulfonic acid groups on the polymer backbone, which is obviously named as Nafion. It has been widely used in the PEM flow cell and $\mathrm{H}$-type $\mathrm{CO}_{2} \mathrm{R}$ reactors because of its outstanding proton transfer property. Though the ion transport depends on the $\mathrm{pH}$ of the reaction medium, proton conduction by PEM will take place thorough sulfonic acid groups $\left(\mathrm{R}-\mathrm{SO}_{3} \mathrm{Na}\right)$ in the presence of alkaline solution (e.g., $\mathrm{NaOH})$. It is well known that in the lower $\mathrm{pH}$ condition, the transport of anions such as $\mathrm{SO}_{4}{ }^{2-}, \mathrm{Cl}^{-}$, and $\mathrm{NO}_{3}{ }^{-}$ are available as the dissociated states by the occurrence of protons. Such anions are blocked owing to the Donnan exclusion effect and therefore the permeability via PEM is very feeble. Conversely, weak acid anions $\left(\mathrm{F}^{-}\right.$and $\left.\mathrm{NO}_{2}{ }^{-}\right)$in their state

Table 2 Performances and results of $\mathrm{CO}_{2} \mathrm{R}$ to formic acid/formate $\left(\mathrm{HCOOH} / \mathrm{HCOO}^{-}\right)$by $\mathrm{CO}_{2}$ reactors with different designs

\begin{tabular}{|c|c|c|c|c|c|c|}
\hline Reactor design & Electrocatalysts & Electrolyte & $\begin{array}{l}\text { Potential (V } \\
\text { vs. RHE) }\end{array}$ & $\begin{array}{l}\text { Current density } \\
\left(\mathrm{mA} \mathrm{cm}^{-2}\right)\end{array}$ & FE $(\%)$ & Ref. \\
\hline \multirow[t]{4}{*}{ H-cell } & Electrodeposited Bi dendrites & $0.5 \mathrm{M} \mathrm{KHCO}_{3}$ & -1.0 & 38.1 & 92 & 61 \\
\hline & Sulfur-doped indium & $0.5 \mathrm{M} \mathrm{KHCO}_{3}$ & -0.98 & $\sim 60$ & 93 & 63 \\
\hline & $\mathrm{PdPt} / \mathrm{C}$ & $0.1 \mathrm{M} \mathrm{K}_{2} \mathrm{HPO}_{4} / 0.1 \mathrm{M} \mathrm{KH}_{2} \mathrm{PO}_{4}$ & -0.4 & 5 & 88 & 64 \\
\hline & Bi-PMo nanosheets & $0.5 \mathrm{M} \mathrm{NaHCO}_{3}$ & -0.86 & 30 & 93 & 65 \\
\hline & Sn nanoparticles (commercial) & $1 \mathrm{M} \mathrm{KOH}$ anolyte & -0.2 & 51.7 & 93.3 & 31 \\
\hline & Sn/C-GDE & DI water & 3.3 & 140 & 94 & 50 \\
\hline & 2D-Bi GDE & $0.25 \mathrm{M} \mathrm{K}_{2} \mathrm{SO}_{4}$ & 3 & 30 & 80 & 34 \\
\hline \multirow[t]{3}{*}{ GDE } & $\mathrm{SnO}_{x}-\mathrm{CNT}$ & $0.5 \mathrm{M} \mathrm{KHCO}_{3}$ & -1.25 & 10 & 77 & 68 \\
\hline & Ru, Pd alloy particles & $0.5 \mathrm{M} \mathrm{KHCO}_{3}$ & $-1.1 \mathrm{~V} v s . \mathrm{NHE}$ & 80 & 90 & 69 \\
\hline & CuSn alloy particles & $1 \mathrm{M} \mathrm{KOH}$ & -1.0 & 148 & 82 & 70 \\
\hline & Sn nanostructure & - & -0.7 & 5 & 12.5 & 37 \\
\hline & $\mathrm{SnO}_{2}$ catalyst carbon black & $1.0 \mathrm{M} \mathrm{KOH}$ & -1.43 & 251 & 80 & 74 \\
\hline \multirow[t]{3}{*}{ MR } & $\mathrm{RuPd} / \mathrm{Sn}$ & $0.5 \mathrm{M} \mathrm{KCl}+1 \mathrm{M} \mathrm{HCl}$ & -0.55 & 100 & 89 & 56 \\
\hline & Sn nanocatalyst/graphite rod & $0.5 \mathrm{M} \mathrm{KHCO}_{3}$ & 2.5 & - & 84.25 & 75 \\
\hline & $\mathrm{SnO}_{2}$ nanoparticles & $1 \mathrm{M} \mathrm{KOH}$ & 0.95 & 147 & 97 & 76 \\
\hline
\end{tabular}


diminish the Donnan exclusion effect and thus increase the permeation rate. ${ }^{80} \mathrm{Wu}$ et $a l .{ }^{37}$ introduced the buffer layer of $\mathrm{KHCO}_{3}$ between the cathode Sn catalyst and the PEM (Nafion 212) in the PEM flow cell for the production of $\mathrm{HCOO}^{-}$. It is found that $\mathrm{CO}_{2} \mathrm{R}$ has led to the $\mathrm{FE}$ of $70 \%$ by the buffer layer while suppressing the $\mathrm{H}_{2}$ evolution reaction. This dictates that ion management depends on the selection of the membrane, which is indispensable for the flow cell. In another study, $\mathrm{CO}_{2} \mathrm{R}$ in a zero gap flow cell equipped with Nafion by the In-Pb bimetallic catalyst produced $80 \% \mathrm{FE}$, which further reduced after $1 \mathrm{~h}$ as a result of diffusion barriers occurring at the interface of the membrane and the electrode. ${ }^{81}$ A comparative investigation between PEM and BPM has been reported by Ramdin et $a l .{ }^{36}$ under a pressure of 50 bar in the flow cell. The generation of $\mathrm{HCOO}^{-}$is assessed by supplying a high-pressure $\mathrm{CO}_{2}$ gas to the cathodic compartment and $90 \%$ of $\mathrm{FE}$ is observed for the pressure of 40 bar. As the reduction reaction keeps on increasing, $\mathrm{HCOO}^{-}$crossover is seen via PEM in the form of variation in the $\mathrm{pH}$ between the compartments and this limitation is addressed with BPM. In general, the membrane thickness also plays a significant role in the product formation, as described by $\mathrm{Li}$ and Oloman et $a .^{82}$ In most of the cases, Nafion 117 with a thickness $180 \mu \mathrm{m}$ has been adopted as the electrolyte; however, only a few articles have dealt with the thinner Nafion 115 having $127 \mu \mathrm{m}$ thickness, leading to the loss of the catholyte owing to product crossover. It is worth noting that even Nafion 117 also undergoes a problem associated with $\mathrm{HCOO}^{-}$crossover with catholyte feeding. Hence, it is not only mandatory to study the membrane thickness but also other properties such as the membrane surface, water uptake, and the ionic conductivity, which need to be thoroughly assessed for an efficient $\mathrm{CO}_{2} \mathrm{R}$ process.

\subsection{Anion exchange membrane}

Anion exchange membrane (AEM) allows transiting the anions while holding the cations and is also known as the hydroxide conducting membrane due to the conduction of hydroxide $\left(\mathrm{OH}^{-}\right)$. One of the properties of AEM is the reduction of crossover of the gas molecules (hydrogen and oxygen) in the $\mathrm{CO}_{2} \mathrm{R}$ electrolyzers. The AEM originates from polymer backbones such as poly(arylene ethers) derivatives (polysulfones, poly(ether ketones)) functionalized with quaternary ammonium anion exchange sites. ${ }^{83}$ The $\mathrm{CO}_{2} \mathrm{R}$ reactor equipped with AEM consists of a strong anolyte at the anode compartment, which facilitates the conductivity and oxygen evolution reaction. The conducting species such as $\mathrm{OH}^{-}, \mathrm{HCO}_{3}{ }^{-}$, and $\mathrm{CO}_{3}{ }^{2-}$ ions are formed at the cathode during product formation and this transfer via the AEM separator to anode compartment. The major issue with AEM is $\mathrm{CO}_{2}$ pumping to the anode in the presence of the anion electrolyte. In order to understand the apparent consumption of product formation and $\mathrm{CO}_{2}$ pumping, Ma et al. ${ }^{84}$ carried out a systematic study on the $\mathrm{CO}_{2}$ utilization in AEM type $\mathrm{CO}_{2}$ reactors. Unfortunately, $70 \%$ of consumed $\mathrm{CO}_{2}$ got pumped out to the anodic compartment and 30\% remains for product formation. The three-compartment reactor using Sn catalyst on GDE with proprietary Sustanion AEM imidazole has delivered a current density $140 \mathrm{~mA} \mathrm{~cm}^{-2}$ and $\mathrm{FE}$ of $94 \%$ over $500 \mathrm{~h}$ toward formic acid..$^{50}$ In addition, Kaczur et al. ${ }^{85}$ reported a remarkable $\mathrm{CO}_{2}$ toward $\mathrm{HCOO}^{-}$conversion efficiency of $99.2 \%$ with a current density of $100 \mathrm{~mA} \mathrm{~cm}^{-2}$ using $\mathrm{Sn}$ as the cathode electrocatalyst and Sustainion X37-50 as the membrane separator. It is important to emphasize that $\mathrm{CO}_{2} \mathrm{R}$ to $\mathrm{HCOOH} /$ $\mathrm{HCOO}^{-}$utilizing AEM is scarce due to the increased ohmic losses, instability in strong alkaline solutions, and product crossover issues due to the $\mathrm{pH}$ variation among the respective compartments. Hence, the proper selection of AEM derivatives has an indispensable role in the mass transfer of $\mathrm{CO}_{2}$ within the compartments and the kinetics of the $\mathrm{CO}_{2} \mathrm{R}$ process.

\subsection{Bipolar membrane}

BPM is manufactured by the stacking of cation and anion exchange layers forming the interface and it can be operated either in forward bias or reverse bias to drive the electrochemical reactions. When the reaction is performed under forward bias, the cation or proton exchange layer (PEL) is kept toward the anodic compartment while the anion exchange layer is directed to the cathodic compartment (vice versa for reverse bias). On the one hand, the oxygen evolution reaction commences at the anode by proton formation as it requires a stable noble metal oxide electrocatalysts such as $\mathrm{IrO}_{2}$. On the other hand, $\mathrm{CO}_{2}$ reduction will occur at the cathode side resulting from the creation of $\mathrm{OH}^{-}$ions and bicarbonate species. In fact, AEM shows good conductivity toward $\mathrm{OH}^{-}$and $\mathrm{HCO}_{3}{ }^{-}$when the Donnan effect co-ion exclusion has no influence. Importantly, the recombination of $\mathrm{H}^{+}$and $\mathrm{OH}^{-}$ions at the interface of PEM/AEM forms water and the bicarbonate species react with $\mathrm{H}^{+}$to yield $\mathrm{CO}_{2}$ as this is a pumping issue in the case of AEM. For the efficient $\mathrm{CO}_{2} \mathrm{R}$ process, the operation of BPM under reverse bias is more feasible as compared to forward bias because the water splitting reaction is encountered at the PEM/ AEM interface. Though the reverse bias enables AEM toward the anode with the flow of alkaline electrolyte and the CEM at the cathode accepts the $\mathrm{CO}_{2}$ feed, the water splitting reaction leads to the accumulation of $\mathrm{H}^{+}$ions at the acidic CEM side and $\mathrm{OH}^{-}$ ions at the AEM side. ${ }^{86}$ The underlying mechanism behind water splitting at the BPM interface is caused by proton transfer between the water and the fixed groups and the enriched electric field behavior described by second Wien's consequence from the Onsager's theory. ${ }^{87,88}$ As discussed earlier, $\mathrm{H}^{+}$and $\mathrm{OH}^{-}$ ions are formed during reverse bias and are transferred from the BPM interface to the cathode and anode. As a result, this balances the overall $\mathrm{H}^{+}$and $\mathrm{OH}^{-}$ions at the reduction process, which in turn maintains the $\mathrm{pH}$. Compared to monopolar membranes, BPM excels in $\mathrm{pH}$ stabilization for the better design and optimization of the economic $\mathrm{CO}_{2} \mathrm{R}$ reactors, as discussed in the literature. ${ }^{79,89,90}$ When $\mathrm{CO}_{2} \mathrm{R}$ is carried out for $\mathrm{HCO}_{3}{ }^{-}$salts under reverse bias, $\mathrm{H}^{+}$ions accumulate at the cathode. The acid-base equilibrium among $\mathrm{H}^{+}$ions and $\mathrm{HCO}_{3}{ }^{-}$ creates $\mathrm{CO}_{2}$ and water (eqn (1) and (2)) near the membrane solution interface, which have a profound impact on the efficiency of the $\mathrm{CO}_{2} \mathrm{R}$ reaction at the cathode. Besides, the migration of $\mathrm{HCO}_{3}{ }^{-}$to the anode is highly hampered owing to 
the Donnan exclusion effect and the transfer of $\mathrm{H}^{+}$is promoted at the CEM in such a way that the $\mathrm{CO}_{2}$ pumping issue experienced in AEM

$$
\begin{aligned}
& \mathrm{HCO}_{3}{ }^{-}+\mathrm{H}^{+} \rightarrow \mathrm{H}_{2} \mathrm{O}+\mathrm{CO}_{2} \\
& \mathrm{CO}_{3}{ }^{2-}+2 \mathrm{H}^{+} \rightarrow \mathrm{H}_{2} \mathrm{O}+\mathrm{CO}_{2}
\end{aligned}
$$

by $\mathrm{HCO}_{3}{ }^{-}$and $\mathrm{CO}_{3}{ }^{2-}$ at the anodic compartment is remarkably curtailed..$^{78}$ Consequently, $\mathrm{CO}_{2} \mathrm{R}$ reactors functioning with BPM makes $\mathrm{HCO}_{3}{ }^{-}$a major thread for the enhancement of local $\mathrm{CO}_{2}$ concentration in the cathode rather than the solubility limit of $\mathrm{CO}_{2}$ in the aqueous media. This in turn provides a novel way to facilitate the current density of the liquid phase $\mathrm{CO}_{2} \mathrm{R}$. At the end, the BPM in the context of water splitting at monopolar junctions displays the minimization of product crossover over CEM and AEM as they possess a low capacity for stabilizing the pH. For example, Zhou et al. ${ }^{90}$ used the conventional H-type cell to study the $\mathrm{CO}_{2} \mathrm{R}$ performance of the cathode electrocatalyst as the $\mathrm{Pd} / \mathrm{C}$ nanoparticle coated $\mathrm{Ti}$ with the bipolar membrane (Fumasep FBM-PK). A maximal current density of $8.5 \mathrm{~mA} \mathrm{~cm} \mathrm{~cm}^{-2}$ and the $94 \%$ of $\mathrm{FE}$ for $\mathrm{CO}_{2}$ reduction to formate in $2.8 \mathrm{M} \mathrm{KHCO}_{3}$ have been obtained. Even though BPM shows several advantages over CEM and AEM, the research investigations on $\mathrm{CO}_{2} \mathrm{R}$ for $\mathrm{HCOOH} / \mathrm{HCOO}^{-}$are not well explored; rather, notable reports are available on the gaseous products such as $\mathrm{CO} \cdot{ }^{86,91} \mathrm{~A}$ large amount of potential develops at BPM under reverse bias, thereby increasing the required voltage for $\mathrm{CO}_{2} \mathrm{R}$, declining the efficiency. This intensified the scientific community to further take forward the research directions on advanced BPM-based $\mathrm{CO}_{2} \mathrm{R}$ reactors for large scale applications. Table 3 demonstrates that progress has been made on $\mathrm{CO}_{2} \mathrm{R}$ toward $\mathrm{HCOOH} /$ $\mathrm{HCOO}^{-}$using different ion exchange membranes.

In this section, it is elucidated that the membrane is one of the principle factors to tailor the electrochemical $\mathrm{CO}_{2}$ reduction for the desired product. Therefore, the polymer electrolyte membranes used in the PEM fuel cells can also be subjected to $\mathrm{CO}_{2}$ electrolyzers to attain the performance metrics necessitated for commercial implementation. It is described as the optimal performance of the CEM and AEM should possess a good swelling property, selectivity, and ionic conductivity. To date, Nafion CEM is a well-developed membrane and considered as an efficient component for $\mathrm{CO}_{2}$ reduction into $\mathrm{HCOOH} / \mathrm{HCOO}^{-}$. Further, the increased selectivity and swelling characteristics of BPM are essential for efficient water dissociation at the interface, which in turn decreases the membrane voltage and increases the energy efficiency.

\section{Selectivity of $\mathrm{CO}_{2}$ electrolyzers}

The selectivity of $\mathrm{CO}_{2} \mathrm{R}$ products is not only governed by the nature of the catalyst, morphology, temperature, pressure, potential, current density, pH, electrolyte media, aqueous or non-aqueous solvents, and membranes but also by the electrochemical reactor configurations. ${ }^{36}$ Successful attempts have been made with continuous-flow electrolyzers of reasonable size $\left(300 \mathrm{~cm}^{2}\right.$ ), delivering the CD (over $100 \mathrm{~mA}$ $\mathrm{cm}^{-2}$ ), durability (h to several months), and high product selectivity (mostly $\mathrm{HCOOH} / \mathrm{HCOO}^{-}$and $\mathrm{CO}$ ). For example, one of the unique $\mathrm{CO}_{2}$ electrolyzers was developed to produce pure $\mathrm{HCOOH}$ based on three-compartment design. The generation of water electrolysis has been done using mixed metal oxide-coated Ti anode and AEM was deployed to prevent the transfer of $\mathrm{HCOO}^{-}$to the anode. This peculiar configuration has makes contact as the zero-gap between the anodic compartment and the anode membrane and the optimal FE of $85-95 \%$ for $\mathrm{HCOOH}$ (5 to $30 \mathrm{wt} \%$ ) was produced with a large CD of $140-200 \mathrm{~mA} \mathrm{~cm}^{-2} \cdot{ }^{94}$ In a microfluidic cell configuration, a very narrow ( $\sim 1 \mathrm{~mm}$ thick) dual channel electrolyte arrangement enabled a high product selectivity of $95 \%$ for $\mathrm{HCOOH}$ and $\mathrm{CD}>300 \mathrm{~mA} \mathrm{~cm}{ }^{-2}$. The effect of micro-channel thickness was found to be one of the crucial factors for the desired products. ${ }^{95}$ Interestingly, the production of $\mathrm{HCOOH}$ acquired a notable difference in the current density, overpotential, and $\mathrm{FE}$ or selectivity when the $\mathrm{CO}_{2} \mathrm{R}$ reaction was changed from the liquid phase to gas phase electrolysis. ${ }^{\mathbf{9 6}}$ Based on the above discussions and prior observations, ${ }^{97}$ it is understood that the product selectivity can be highly tailored by the partial pressure of $\mathrm{CO}_{2}$ and components (GDE, MEA, membrane, etc.) of the electrolyzer. Ultimately, such factors vary for different configurations and hence the selectivity of $\mathrm{CO}_{2} \mathrm{R}$ also varies.

\begin{tabular}{|c|c|c|c|c|c|c|}
\hline \multirow[t]{4}{*}{ CEM } & Nafion 211 & Sn & $0.1 \mathrm{M} \mathrm{KHCO}_{3}$ & 15 & 91 & 28 \\
\hline & Nafion 212 & Sn & $0.1 \mathrm{M} \mathrm{KHCO}_{3}$ & -9 & 90 & 37 \\
\hline & Nafion 117 & $\mathrm{SnO}_{2}$ & $0.5 \mathrm{M} \mathrm{KHCO}_{3}$ & 12.5 & 62 & 92 \\
\hline & Nafion 117 & $\mathrm{Cu}$ & $0.5 \mathrm{M} \mathrm{KHCO}_{3}$ & - & 60 & 93 \\
\hline & Sustainion X37-50 & Sn/PTFE & $\mathrm{CO}_{2}$ & 140 & 94 & 50 \\
\hline & AMI-7001S & $\mathrm{In}-\mathrm{Pb} / \mathrm{C}$ & $1 \mathrm{M} \mathrm{NaHCO}_{3}$ & 40 & 80 & 83 \\
\hline \multirow[t]{2}{*}{ BPM } & Fumasep FBM-PK & Sn & $0.5 \mathrm{M} \mathrm{KHCO}_{3}$ & 90 & 30 & 36 \\
\hline & Fumasep FBMPK & $\mathrm{Pd} / \mathrm{C}$ & $2.8 \mathrm{M} \mathrm{KHCO}_{3}$ & 8.5 & $\sim 100$ & 91 \\
\hline
\end{tabular}

Table 3 The comparison of $\mathrm{CO}_{2} \mathrm{R}$ performances to $\mathrm{HCOOH} / \mathrm{HCOO}^{-}$by different ion exchange membranes (CEM, AEM and BPM) 


\section{Fabrication of $\mathrm{CO}_{2}$ electrolyzers and membranes}

\section{$5.1 \mathrm{CO}_{2}$ electrolyzers}

The $\mathrm{CO}_{2}$ electrolyzer is often fabricated with either in two or three compartments wherein the anodic and cathodic counterparts are separated by an oxidant-resistant permeable ion exchange membrane. These compartments are machined using thick acrylic plastic or polytetrafluoroethylene with the required dimensions. The anodic compartment was packed with a thick titanium anode back plate on one side bearing gold coating (2.54 microns) and a long titanium post on the other side. The conductor posts were tightened via holes from the outside of the anodic compartment. In order to prevent the fluid from flowing away from the anodic back plate, the gold-coated titanium plate was glued and sealed in inside the compartment with a silicone adhesive. On the other hand, the cathodic compartment was packed with perforated stainless-steel plate with a similar dimension as that of the anodic compartment. The ionic exchange membrane was sandwiched between the anodic and cathodic compartments; thereby, the cell assembly was completed using rubber gasket glued to each compartment's surface. Finally, the $\mathrm{CO}_{2}$ electrolyzer was compressed and sealed with nuts and bolts and allowed for DC power supply. However, the cell fabrication material was suggested to be corrosion-resistant as acrylic and other materials such as titanium, tantalum, zirconium, polyethylene, and polystyrene can also be utilized. Depending upon the requirements and modifications, three compartments and stacked electrolyzers can also be fabricated to promote the $\mathrm{CO}_{2} \mathrm{R}$ reaction and figure of merits. $^{98}$

\subsection{Membranes}

The frequently-used cationic exchange membrane Nafion is made up of perfluorosulfonic acid (PFSA) groups consisting of perfluorocarbon backbones with side chains terminated with sulfonated groups. The precursor PFSA is usually converted into resin ( $\mathrm{H}^{+}$type) using $6 \mathrm{M} \mathrm{NaOH}$ and $2 \mathrm{M} \mathrm{H}_{2} \mathrm{SO}_{4}$ aqueous solutions under stirring for a long time. Thereafter, the PFSA resin was dissolved in $N, N$-dimethylformamide (DMF) in an autoclave for $230{ }^{\circ} \mathrm{C}$ to attain $5 \mathrm{wt} \%$ solution. Then, the solution was condensed to $13.6 \mathrm{wt} \%$ and was casted onto a glass plate with the help of a stainless-steel scraper. Followed by this, it was again kept in an oven at $180{ }^{\circ} \mathrm{C}$ for $4 \mathrm{~h}$. After the oven temperature was cooled down to the room temperature, the PFSA membrane with a desired thickness (in terms of microns) was peeled off from the glass plate. Further, it was soaked in $1 \mathrm{M}$ $\mathrm{KOH}$ solution for $24 \mathrm{~h}$ to activate the ion exchange and its capacity was finally determined by the titration method.99,100 Similarly, the anion exchange membranes bearing a variety of precursors, e.g., poly(arylene ethers), polysulfones, and poly(ether ketones), are dissolved in dimethyl sulfoxide (DMSO) with a content of $5 \mathrm{wt} \%$. Then, the solution was filtered and cast onto a glass plate. The resultant glass plate was heated at $80{ }^{\circ} \mathrm{C}$ for $12 \mathrm{~h}$ to yield the membrane. Then, the above membrane on a glass plate was soaked in water until it was automatically peeled off from the plate. At last, the membrane was submerged in $1 \mathrm{~mol} \mathrm{~L}^{-1} \mathrm{NaOH}$ solution for $48 \mathrm{~h}$ and finally washed with deionized water. ${ }^{101}$ The bipolar membrane can be prepared by choosing proper cationic (e.g., Nafion NR-211) and anionic membrane layers (e.g., hexamethyl-p-terphenyl poly(benzimidazolium), known as PBI). To begin, PBI in the iodide form was changed to the $\mathrm{OH}^{-}$form by immersing the membrane layer in $1 \mathrm{M} \mathrm{KOH}$ for $48 \mathrm{~h}$ at room temperature. Further, the membrane was washed several times with deionized water, followed by soaking for few days prior to usage. On the other side, Nafion was transferred to the $\mathrm{H}^{+}$form by soaking in $\mathrm{H}_{2} \mathrm{SO}_{4}$ for a day. After several washes with deionized water, the membrane was kept in the same for a longer duration. Then, BPM was fabricated with or without the interlayer (e.g., polyethylene glycol) by laminating with the help of posttreatment processes such as a hot melt or solvent fumigation. Due to the electrostatic force of attraction, the Nafion and PBI membranes were adhered together when they were placed one over another. According to the procedure followed for AEM or CEM, BPM can also be prepared step-by-step by taking the initial precursors of the desired membranes with or without the interlayer. ${ }^{102,103}$

\section{Electrocatalysts}

To track the targeted chemicals/fuels along with the enriched current density, feeble overpotential, and long-term stability, the proper choice of electrocatalysts is essential so as to make the device operational cost lesser and increase the energy efficiency. The electrocatalysts subjected to the $\mathrm{CO}_{2} \mathrm{R}$ process can be classified into homogeneous and heterogeneous, where the former could be homogeneously dispersed in the electrolyte to activate a large contact area, leading to high utilization efficiency. However, heterogeneous electrocatalysts have been reserved for $\mathrm{CO}_{2} \mathrm{R}$ because of the easy separation of the products from the electrolyte and catalyst recyclability. The product selectivity is primarily tackled by exploring the relationship between the binding affinities and strength of the intermediates and the electrocatalyst surface. The plausible reaction intermediates are ${ }^{*} \mathrm{OCHO},{ }^{*} \mathrm{COOH},{ }^{*} \mathrm{CO}$, and ${ }^{*} \mathrm{H}\left(\right.$ for $\left.\mathrm{H}_{2}\right)$, in which the adsorption of ${ }^{*} \mathrm{OCHO}$ and ${ }^{*} \mathrm{COOH}$ is via the endothermic reaction. Formic acid or formate is produced by the catalyst surface, which stabilizes the *OCHO rather than ${ }^{*} \mathrm{COOH}$, thus favoring carbon monoxide. ${ }^{104,105}$ Based on the above predictions, $\mathrm{CO}_{2} \mathrm{R}$ to $\mathrm{HCOOH} / \mathrm{HCOO}^{-}$conversion is performed so far with metal-based (group II metals) and metal-free (carbon, $\mathrm{N}$ (B)-doped carbon materials) electrocatalysts. Due to the poor electronic conductivity and selectivity, the metal free electrocatalysts hinder their application in $\mathrm{CO}_{2} \mathrm{R}$ toward $\mathrm{HCOOH} /$ $\mathrm{HCOO}^{-}$. Thus, metals such as $\mathrm{Pb}, \mathrm{Pd}, \mathrm{Sn}, \mathrm{Bi}, \mathrm{In}, \mathrm{Hg}, \mathrm{Cd}, \mathrm{Sb}$, and Co have been well established as electrocatalysts for the $\mathrm{CO}_{2} \mathrm{R}$ toward $\mathrm{HCOOH} / \mathrm{HCOO}^{-}$; however, recently, $\mathrm{Pb}, \mathrm{Sn}, \mathrm{Bi}$, and In have become popular electrocatalysts when alloying, doping, and compositing for efficient $\mathrm{CO}_{2} \mathrm{R}$ because doping and alloying are the most predominant ways to develop new electrocatalysts, thereby affecting the electronic structure and their association with selectivity and activity of $\mathrm{CO}_{2} \mathrm{R}$ toward $\mathrm{HCOOH} / \mathrm{HCOO}^{-}$. 
Therefore, the current section particularly aids very recent developments on $\mathrm{Pb}, \mathrm{Sn}, \mathrm{Bi}$, and In catalysts to the readers as there are already significant progresses made on the same catalysts. ${ }^{106}$

Despite the intrinsic toxicity and environmental unfriendliness of $\mathrm{Pb}$, it is of fundamental interest to assess $\mathrm{CO}_{2} \mathrm{R}$ owing to its excellent selectivity toward $\mathrm{HCOOH} / \mathrm{HCOO}^{-}$, which shows the similarities and discrepancies compared to main group electrocatalysts. $\mathrm{Pb}$ electrodes in the form of flat plates, nanowires, and granules have been demonstrated to be the catalyst for $\mathrm{CO}_{2} \mathrm{R}^{107,108}$ For instance, $\mathrm{PbS}$ nanocrystals prepared under in situ electrochemical $\mathrm{CO}_{2} \mathrm{R}$ conditions reveal $\mathrm{CO}_{2}$ to $\mathrm{HCOO}^{-}$ conversion $>97.6 \pm 5.3 \%$ of $\mathrm{FE}$ at $-1.2 \mathrm{~V}$ and a maximal mass activity of $74.9 \pm 4.7 \% \mathrm{~mA} \mathrm{mg}_{\mathrm{Pb}}{ }^{-1}$ at $1.4 \mathrm{~V}$. Besides, in situ synchrotron $\mathrm{X}$-ray diffraction unraveled the structural evolution of $\mathrm{PbS}$ via $\mathrm{PbCO}_{3}-\mathrm{Pb}$ as a result of increased concentration of the $\mathrm{CO}_{2} / \mathrm{HCO}_{3} / \mathrm{CO}_{3}{ }^{2-}$ species. ${ }^{109}$ In another study, 3D layered porous CNT aerogel hybridized with $\mathrm{Pb}$ nanoparticles showed stable $\mathrm{CO}_{2}$ reduction performance for $10 \mathrm{~h}$ with a $\mathrm{FE}$ of $84.6 \%$ and a current density of $28 \mathrm{~mA} \mathrm{~cm} \mathrm{~cm}^{-2}$ for the production of $\mathrm{HCOO}^{-}$. This excellent activity is attributed to the typical 3D porous structure, large specific surface area, and favorable conductive network, leading to promoted selectivity. ${ }^{\mathbf{1 1 0}}$ One of the interesting approaches by Widiatmoko et al. has reported alloy fabrication using the $\mathrm{Pb}-\mathrm{Sn}$ combination for the separation of $\mathrm{HCOOH}$. It is found that the productivity and selectivity were higher in $\mathrm{KHCO}_{3}$ when compared to $\mathrm{NaHCO}_{3}$. The maximum amount of $\mathrm{HCOOH}$ is observed to be $9400 \mu \mathrm{mol}$ with an FE of $67.19 \%$ and the electrode is stable over a period of $7 \mathrm{~h}$ of electrolysis. ${ }^{\mathbf{1 1 1}}$ Therefore, a high FE can be obtained against $\mathrm{HCOO}^{-}$using $\mathrm{Pb}$ electrodes even though a higher overpotential is required to drive the $\mathrm{CO}_{2} \mathrm{R}$ reaction compared to $\mathrm{Sn}, \mathrm{Bi}$, and In. Sn-based electrocatalysts display excellent environmental and economic benefits such as abundance, low toxicity, and high selectivity toward $\mathrm{HCOO}^{-}$but with a large overpotential and low current density. Fortunately, Sn catalysts were not only restricted to $\mathrm{HCOO}^{-}$but the selectivity of the product can also be tuned $\left(\mathrm{CH}_{4}\right.$ and $\left.\mathrm{CO}\right)$ by making composites with oxides and zeolites. ${ }^{112}$ It is prone to oxidize under air and its surface is normally covered by oxide layers. These surface oxide layers reduce before taking part in the $\mathrm{CO}_{2} \mathrm{R}$ reaction depending on the standard redox potential. Hence, a large overpotential is necessary for commencing the $\mathrm{CO}_{2} \mathrm{R}$ due to a strong kinetic barrier for electron transfer from $\mathrm{Sn}$ to $\mathrm{CO}_{2}$ to create the initial $\mathrm{CO}_{2}{ }^{--}$intermediate. Nevertheless, long-term stability is a degrading factor in $\mathrm{Sn}$ electrodes, which arises from cathodic deterioration of the Sn surface, formation of non-catalytic species from intermediates, and contaminants from electrolyte. Very recently, Tsujiguchi et al. ${ }^{113}$ investigated the electrochemical $\mathrm{CO}_{2}$ reduction of Sn particles decorated on reduced graphene oxide (rGO) and observed an FE of $98 \pm 0.7 \%$ at $-0.82 \mathrm{~V}$ (Fig. 15a-d). To support this, density functional theory (DFT) calculation predicted the formation of various oxidized functional groups by rGO adjacent to the Sn surface and thus
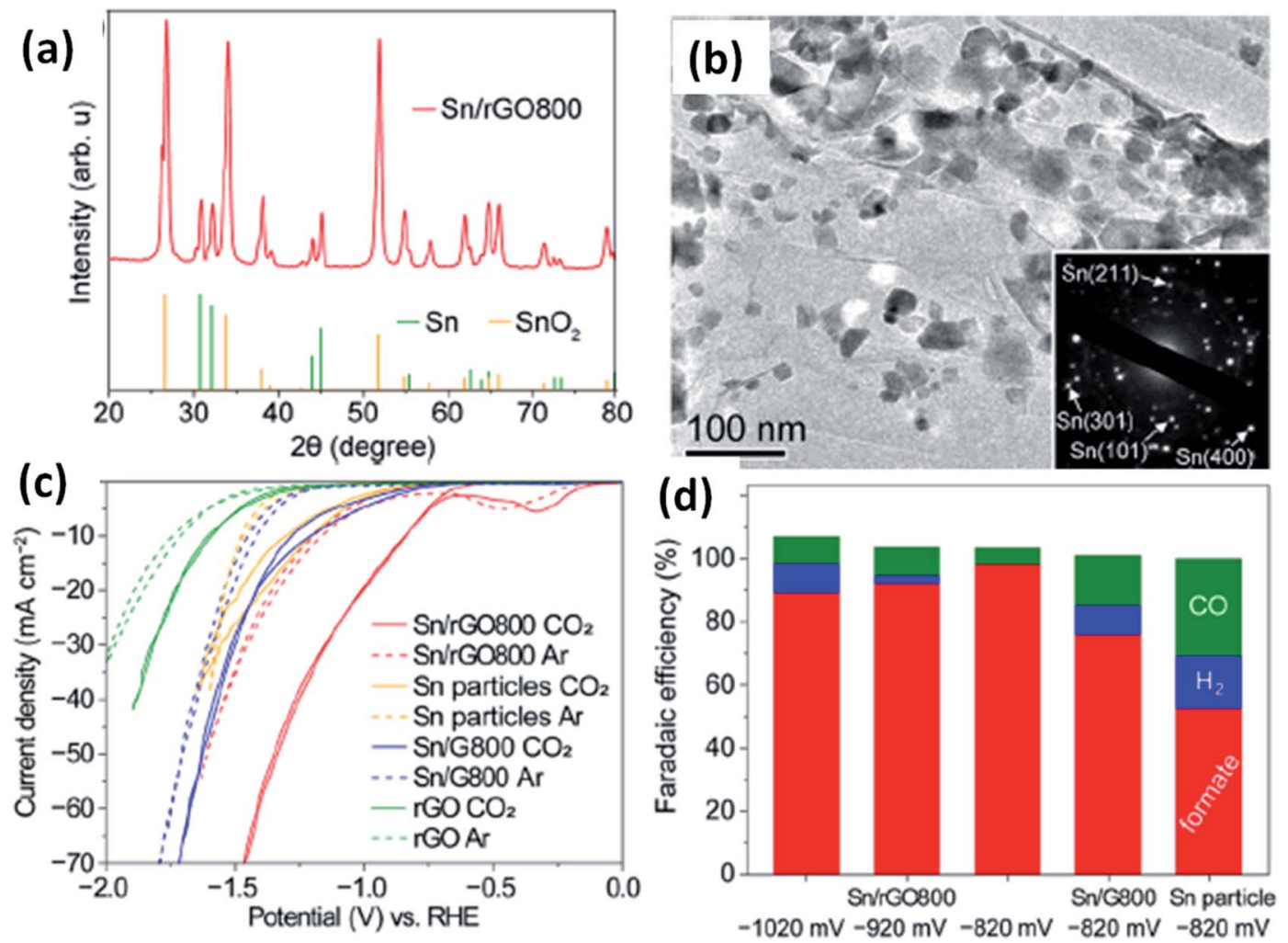

Fig. 15 (a) XRD pattern, (b) TEM micrograph of Sn/rGO composites, (c) hydrodynamic voltammograms of different cathodes with and without rGO, and (d) FE of $\mathrm{HCOO}^{-}, \mathrm{H}_{2}$, and CO for Sn/rGO800, Sn/G800, and Sn particles [ref. 113, Copyright @ 2021, American Chemical Society]. 
the production of $\mathrm{HCOO}^{-}$occurred via the ${ }^{*} \mathrm{COOH}$ intermediate rather than ${ }^{*} \mathrm{CO}$. Similarly, Wen et al. ${ }^{\mathbf{1 1 4}}$ fabricated a highly selective Sn nanosheets decorated with Bi nanoparticles, which were further reduced into $\mathrm{Sn}$ nanosheets to form a $\mathrm{Bi}-\mathrm{Sn}$ bimetallic catalyst. Owing to the orbital interaction of the $\mathrm{Bi}-\mathrm{Sn}$ and $\mathrm{Sn}-\mathrm{O}$ interface, the $\mathrm{Bi}-\mathrm{Sn}$ bimetallic catalyst delivered a remarkable $\mathrm{FE}(96 \%)$ and productive rate $\left(0.07 \mathrm{mmol} \mathrm{h}^{-1}\right.$ $\mathrm{cm}^{-2}$ ) at $-1.1 \mathrm{~V}$ vs. RHE. Beneficially, the catalyst sustained efficiency over a large period of electrolysis time $(100 \mathrm{~h})$. Moreover, DFT calculations elucidated that the loading of Bi nanoparticles lifted the electronic states of Sn just away from the Fermi level, allowing the HCOO* intermediate to adsorb easily at the $\mathrm{Bi}-\mathrm{Sn}$ interface. This facilitated the migration of electrons for the selective and durable conversion of $\mathrm{CO}_{2}$ into $\mathrm{HCOO}^{-}$. Moreover, with the in situ formation of the $\mathrm{SnO}_{2} / \mathrm{Sn}$ heterostructure, an efficient $\mathrm{CO}_{2} \mathrm{R}$ activity was noted against $\mathrm{HCOO}^{-}$, possessing an $\mathrm{FE}$ of $93 \%$ and a partial current density of $28.7 \mathrm{~mA} \mathrm{~cm} \mathrm{~m}^{-2}$ at $-1 \mathrm{~V}$ vs. RHE. It was found that MottSchottky heterojunctions were formed at $\mathrm{SnO}_{2} / \mathrm{Sn}$, which favored the $\mathrm{HCOO}^{-}$productivity while suppressing $\mathrm{H}_{2} \cdot{ }^{115}$ Another pioneering work was carried out by Ito et al. ${ }^{\mathbf{1 1 6}}$ for the phase-dependent $\mathrm{CO}_{2} \mathrm{R}$ performance of NiSn bimetallic alloys, where one of the phases stimulated the primary reaction and other induced the secondary side reaction. NiSn alloys in the forms of $\mathrm{Ni}_{3} \mathrm{Sn}_{4}, \mathrm{Ni}_{3} \mathrm{Sn}$, and $\mathrm{Ni}_{3} \mathrm{Sn}_{2}$ were fabricated and the synergetic impact was identified for $\mathrm{Ni}_{3} \mathrm{Sn}_{4}$; herein, the $\mathrm{Sn}$ concentration is richer, creating more Ni-Sn bonds instead of $\mathrm{Ni}-\mathrm{Ni}$ bonds. Thus, the FE of $\mathrm{HCOO}^{-}$generation of $79.1 \pm 1.5 \%$ was achieved at $-0.8 \mathrm{~V}$ vs. RHE for $\mathrm{Ni}_{3} \mathrm{Sn}_{4}$. This insightful investigation leads to a better understanding of $\mathrm{CO}_{2} \mathrm{R}$ and provides a novel strategy to design bimetallic alloys when mixed with other metals such as Bi and In.

Unlike $\mathrm{Pb}$ and $\mathrm{Sn}, \mathrm{Bi}$ is well-known for its low toxicity and environmental benignity. After the first observation of $\mathrm{CO}_{2} \mathrm{R}$ by Komatsu et al., ${ }^{117}$ it has been developed as a catalyst for CO generation in ionic liquids. However, in recent days, $\mathrm{Bi}$ is one of the leading electrocatalysts for the selective production of $\mathrm{HCOO}^{-}$in aqueous solution and can be simply fabricated by electrodeposition while carefully controlling the deposition potential, time, and base substrate. Importantly, the product formation happened through *OCHO intermediate and ultimately resulted in almost $100 \% \mathrm{FE}$ of $\mathrm{HCOO}^{-}$. To start with, the in situ electrochemical transformation of $\mathrm{BiVO}_{4}$ flakes to bismuthene nanosheets demonstrated a large FE toward $\mathrm{HCOO}^{-}$

(a)
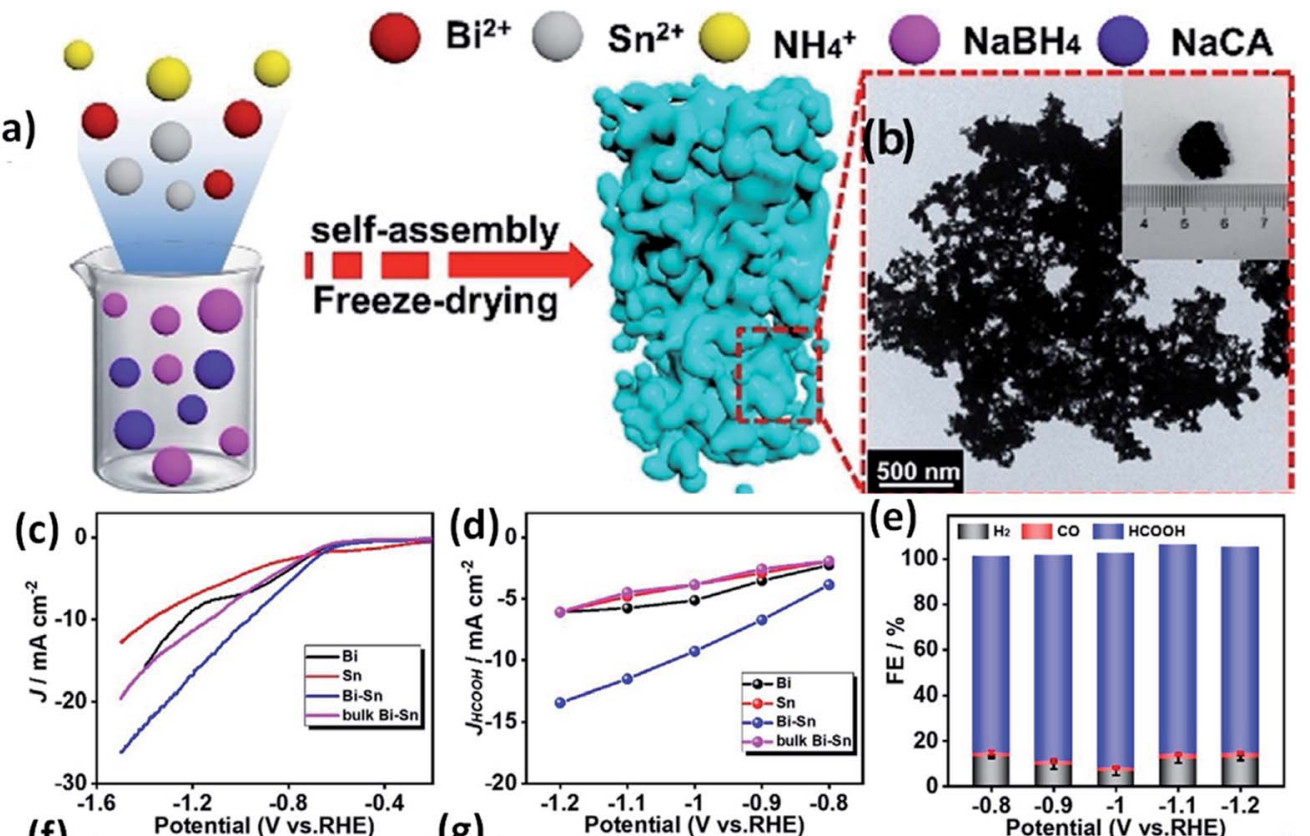

(e)
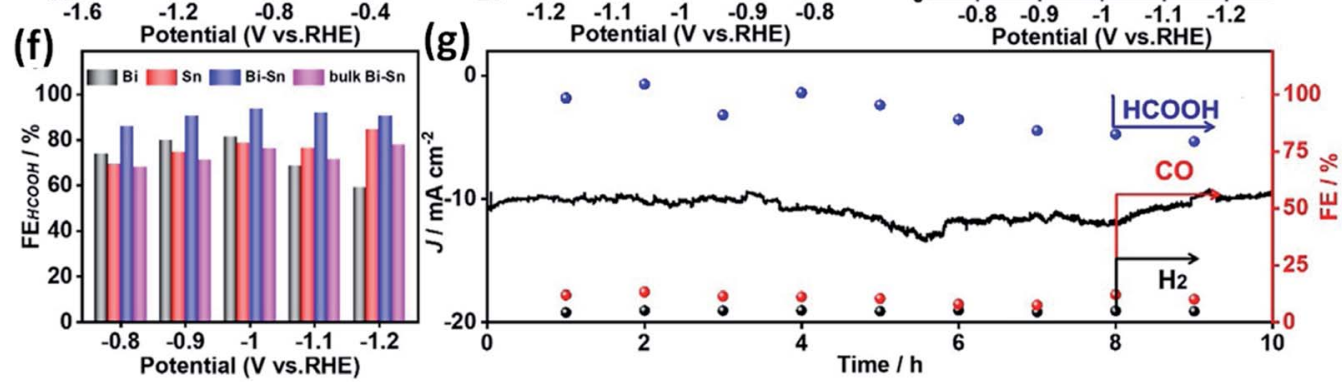

Fig. 16 (a) Representation of the synthesis of $\mathrm{Bi}-\mathrm{Sn}$ aerogel, (b) TEM image of $\mathrm{Bi}-\mathrm{Sn}$, (c) LSV curves of $\mathrm{Sn}, \mathrm{Bi}, \mathrm{Bi}-\mathrm{Sn}$ and bulk Bi-Sn, (d) partial CD for $\mathrm{HCOOH}$ of the prepared electrocatalysts, (e) FEs of various products of $\mathrm{Bi}-\mathrm{Sn}$ aerogels, (f) comparison of $\mathrm{HCOOH} \mathrm{FEs} \mathrm{of} \mathrm{the} \mathrm{synthesized} \mathrm{Bi}$, $\mathrm{Sn}, \mathrm{Bi}-\mathrm{Sn}$ and bulk Bi-Sn at different applied potentials and (g) long term durability study of Bi-Sn for $10 \mathrm{~h}$ [ref. 120, Copyright @ 2021, Wiley-VCH $\mathrm{GmbH}$. 
(97.4\%) and a very huge current density $-105.4 \mathrm{~mA} \mathrm{~cm}^{-2}$ at $-1 \mathrm{~V}$ vs. RHE. Both the experimental and theoretical backgrounds show that the outstanding $\mathrm{CO}_{2} \mathrm{R}$ reaction of the ultrathin bismuthene nanosheets is assigned to the faster kinetics with regards to the HCOO* intermediate in comparison with ${ }^{*} \mathrm{COOH}$ and $\mathrm{H}^{*}{ }^{118}$ Though most of the research efforts have been dedicated to form $\mathrm{HCOO}^{-}$depending upon the catalyst, a novel $\mathrm{Bi}-\mathrm{Sn}$ based bimetallic catalyst has also proven to be efficient for $\mathrm{HCOOH}^{.19}$ In this case, $\mathrm{FE}$ for the production of $\mathrm{HCOOH}$ gradually increased with moles of $\mathrm{Bi}$ in the $\mathrm{Bi}_{x} \mathrm{Sn}_{y}$ catalysts on $\mathrm{Cu}$ and $\mathrm{Bi} / \mathrm{Cu}$ is shown to have promoted the values of current $(30 \mathrm{~mA})$ and $\mathrm{FE}(90.4 \%)$ at $-0.84 \mathrm{~V} v s$. RHE. In addition to this, $\mathrm{Wu}$ et al. ${ }^{\mathbf{1 2 0}}$ prepared a non-precious bimetallic aerogel of $\mathrm{Bi}-\mathrm{Sn}$ with $3 \mathrm{D}$ interconnected channels, abundant interfaces, and hydrophilic surfaces. Unlike pure Bi or Sn, Bi-Sn aerogel exhibited more active sites, endowing a high $\mathrm{FE}(93.9 \%)$ and $90 \%$ against $\mathrm{HCOOH}$ after $10 \mathrm{~h}$ in the flow battery (Fig. 16a-g). This investigation paves a novel way to design non-precious metal aerogels having numerous reactive sites for the selective detection of products. Finally, In-based electrocatalysts almost resemble $\mathrm{Bi}$ and $\mathrm{Sn}$ except its mild toxicity and 10 times higher cost, which become major obstacles in the practical applications. It is a highly oxophilic metal and so, normally, the oxide layer is wrapped on its surface, resulting in poor thermal stability. Meanwhile, the oxide layers still actively take part in the $\mathrm{CO}_{2} \mathrm{R}$ reactions. Hou et al. ${ }^{121}$ realized the efficient $\mathrm{CO}_{2} \mathrm{R}$ on InN-C catalysts in membrane electrode assembly systems. When the reaction is done in aqueous phase, the maximum $\mathrm{FE}$ for $\mathrm{HCOO}^{-}$is found to be $92.2 \%$ at $0.9 \mathrm{~V} v s$. RHE and it is slightly enhanced to $92.5 \%$ at $2.96 \mathrm{~V}$ with a partial current density of $60.1 \mathrm{~mA} \mathrm{~cm}{ }^{-2}$ by membrane electrode assembly electrolysis. Likewise, In-coated gas diffusion electrode enhanced the selectivity of $\mathrm{HCOOH}$ with a notable $\mathrm{FE}(38 \%)$ at $-1.65 \mathrm{~V} v$ s. $\mathrm{Ag} / \mathrm{AgCl}$ in comparison with In foil $(11 \%) .{ }^{122}$ Most recently, In/ZnO@C hollow nanocubes have proven to be a promising electrocatalyst for $\mathrm{CO}_{2} \mathrm{R}$ to $\mathrm{HCOOH}$ via $\mathrm{HCOO}^{*}$ intermediates (Fig. 17a-d). The unique nanocubes exhibited superior catalytic activity and selectivity as the PCD of $23.5 \mathrm{~mA}$ $\mathrm{cm}^{-2}$ with a FE of $90 \%$ at $-1.2 \mathrm{~V}$ vs. RHE. ${ }^{123}$ Since the $\mathrm{CO}_{2}$ reduction activity relies on the nature of the active sites and the surface hydroxyl groups of the electrocatalyst, Li et al. ${ }^{\mathbf{1 2 4}}$ investigated such parameters on electrodeposited Bi, Sn, and In by in situ XRD and DFT calculations. The active sites such as $\mathrm{Bi}^{0}, \mathrm{SnO}$, and $\mathrm{In}_{2} \mathrm{O}_{3}$ with affinities declared that there are two pathways for the production of $\mathrm{HCOO}^{-}$: (i) interaction of $\mathrm{CO}_{2}$ with hydroxyl ions to form bicarbonate species, (ii) hydroxyl free sites of the *OCHO intermediate. The role of hydroxyl species in $\mathrm{CO}_{2} \mathrm{R}$ gives the order $\mathrm{Bi}<\mathrm{Sn}<$ In for the affinity of these species.
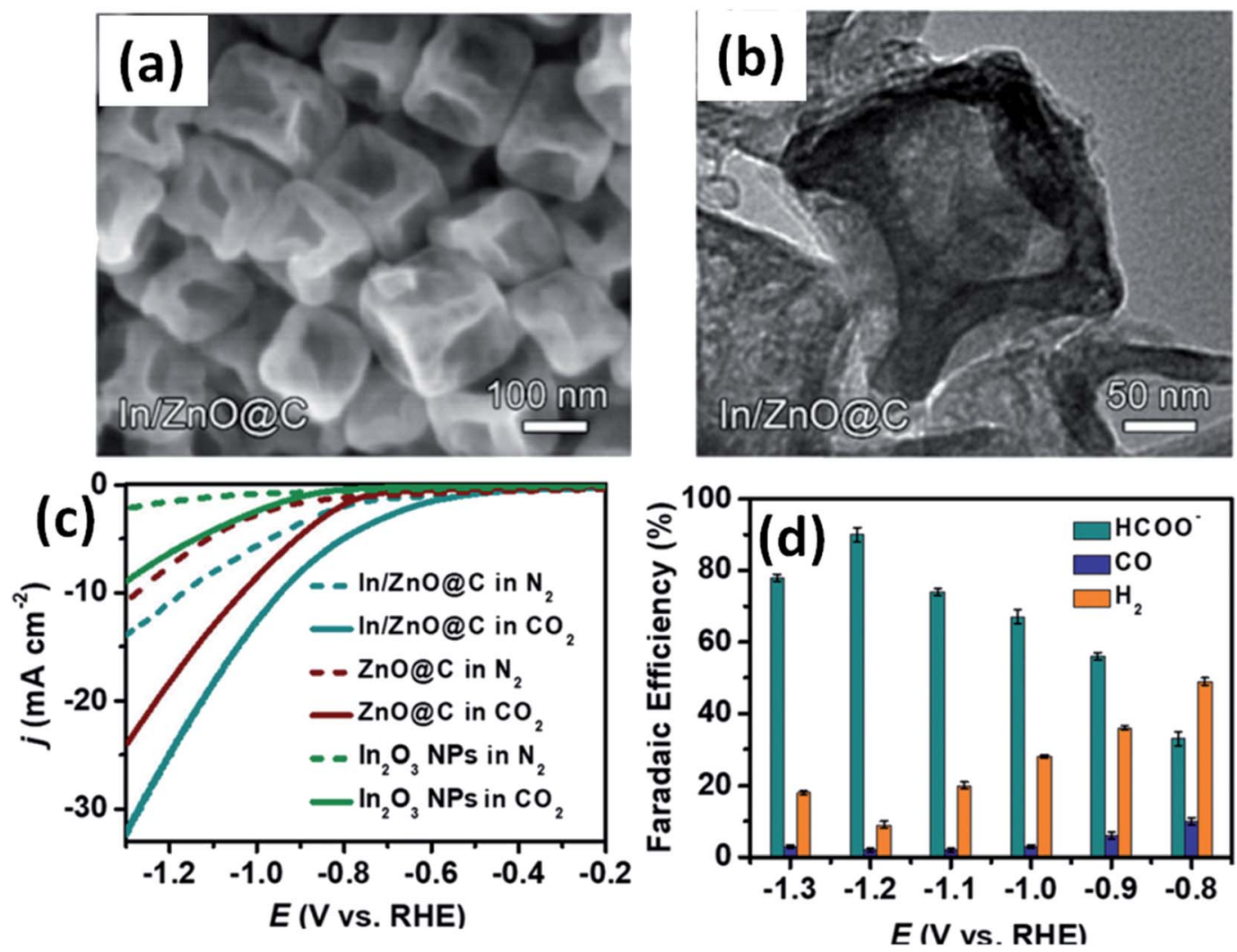

Fig. 17 (a) SEM micrograph, (b) TEM of In/ZnO hollow nanocubes@C, (c) LSV sweeps of In/ZnO@C, $\mathrm{ZnO} \mathrm{CC}$ and $\mathrm{In}_{2} \mathrm{O}_{3}$ nanoparticles in $\mathrm{N}_{2}{ }^{-}$and $\mathrm{CO}_{2}{ }^{-}$saturated $0.5 \mathrm{M} \mathrm{KHCO}_{3}$ solutions and (d) variation of $\mathrm{FE}_{\mathrm{HCOO}^{-}}, \mathrm{FE}_{\mathrm{CO}}$ and $\mathrm{FE}_{\mathrm{H}_{2}}$ for $\mathrm{In} / \mathrm{ZnO} @ \mathrm{C}$ as a function of the applied potential [ref. 123, no permission is required]. 


\section{Economic feasibility and future research directions}

Despite a sufficient number of lab scale experiments that have been performed on $\mathrm{CO}_{2} \mathrm{R}$ to produce several liquid and gas fuels, there have been less attempts so far to establish the foundation of electrolyzer systems at the pilot scale. The current benchmark of $\mathrm{CO}_{2} \mathrm{R}$ in the pilot scale was developed for $\mathrm{CO}$ production by Dioxide Materials using the ionic liquid-assisted MEA and was obtained as the current density $\left(400 \mathrm{~mA} \mathrm{~cm}^{-2}\right)$ for 4500 h. ${ }^{\mathbf{1 2 5}}$ Mantra Venture Group Ltd. (Canada) ${ }^{\mathbf{1 2 6}}$ deployed a pilot plant for capturing $\mathrm{CO}_{2}$ from the Lafarge plant that emits $100 \mathrm{~kg}$ daily and the same was designated for the electrochemical conversion to $\mathrm{HCOO}^{-}$salts that sell for \$1500 per ton. Similarly, a plant for $\mathrm{HCOOH}$ production with a capacity of 10 $\mathrm{kg}$ of $\mathrm{CO}_{2}$ per day was developed by Techwin Co., Ltd. (South Korea). ${ }^{127}$ To further scale up $\mathrm{CO}_{2} \mathrm{R}$, the Det Norske Veritas (DNV, Norway) employed a semi-pilot size reactor (surface area of $600 \mathrm{~cm}^{2}$ ) for the electrochemical reduction of $\mathrm{CO}_{2}$ to $\mathrm{HCOO}^{-} /$ $\mathrm{HCOOH}$ with a reducing capacity of $\sim 1 \mathrm{~kg}$ of $\mathrm{CO}_{2}$ per day. ${ }^{128}$ In 2019, the techno-economic analysis of $\mathrm{CO}_{2} \mathrm{R}$ for the production of $\mathrm{HCOOH}$ was analyzed by De Luna et al. ${ }^{129}$ and the fossil fuelderived electrocatalyst has become cost-effective with electricity costs of 4 cents per $\mathrm{kW} \mathrm{h,} \mathrm{90 \%} \mathrm{FE,} \mathrm{and} \mathrm{70 \%} \mathrm{energy} \mathrm{conversion}$ efficiency compared with that of the biocatalytic process. This brief survey conveys that the production of $\mathrm{HCOO}^{-} / \mathrm{HCOOH}$ has an indispensable scope for commercialization such as $\mathrm{CO}$ and, currently, the research on this domain has expanded globally. Thus, electrolyzer design and membrane are the focus of the present review, which could also determine the efficiency of the figures of merits in the electrochemical $\mathrm{CO}_{2}$ reduction, as highlighted in this perspective. Therefore, achieving a high performance in $\mathrm{CO}_{2}$ electrolyzers not only demands promoted electrokinetics but also requires precise device engineering. ${ }^{130,131}$ To meet a high reaction rate, $\mathrm{CO}_{2} \mathrm{R}$ must be carried out in continuous flow reactors encompassing MEA with GDE, leading to a thin hydrodynamic boundary layer, which allows the strong diffusion of $\mathrm{CO}_{2}$ to the catalyst, resulting in the high current density. In this aspect, flow reactors would be a major development direction in the future and the gas-phase $\mathrm{CO}_{2}$ stream, and relevant polymer electrolyte membrane and gas diffusion electrodes are carefully considered for further industrial application. In addition, the channel length and the flow rate of the $\mathrm{CO}_{2}$ stream associated with $\mathrm{CO}_{2}$ concentration on the cathode surface must also be optimized. Moreover, the highly alkaline environment in MR reveals a current density greater than $1 \mathrm{~A} \mathrm{~cm}^{-2}$; however, now the production is efficient for $\mathrm{CO}$ rather than $\mathrm{HCOOH}$, necessitating further research advancements. To date, the use of zero-gap electrolyzers offers the straight-forward implementation of industrial systems to generate high value-added products with a large energy efficiency. The ultimate goal of CCU will be realized when the electrolyzer design is sufficiently advanced and compatible with the techno-economic requirements. Thus, the industrial processing architecture could be established, safeguarding the world by renewable technology.

\section{Summary and outlook}

Energy crisis and global warming are the most challenging issues existing in the world and the electrochemical $\mathrm{CO}_{2}$ reduction provides unprecedented opportunities to address the above obstacles by closing the carbon cycle. The electrochemical reduction of $\mathrm{CO}_{2}$ to formic acid has great scope as a hydrogen energy carrier, mobility households, and in different industrial sectors. There has been a significant effort made to get the base line current density with FE; however, those are yet to be assessed by the electrocatalysts, electrode modification, and stabilizing the electrolyte. $\mathrm{CO}_{2} \mathrm{R}$ not only depends on such factors but also relies on the reactor design and the membrane structure. Therefore, a series of configurations (H-type, flow cells, microfluidic, and zero-gap reactors), its components (gas diffusion electrodes, membrane electrode assembly), the different types of membranes (proton exchange membranes, anion exchange membranes, and bipolar membranes), and the recent advancement on the catalyst have been reviewed in this perspective to explore scientific insights for efficient $\mathrm{CO}_{2} \mathrm{R}$.

Yet, the conventional $\mathrm{H}$-type reactor is the universal architecture for the $\mathrm{CO}_{2} \mathrm{R}$ screening of a vast amount of catalysts; however, still ER is gaining more attention to observe the enhanced and accurate performance by modifying the position of the reference electrodes and the inside pressure of the reactor. The flow reactors are becoming alternatives to H-type cells, conquering the mass transfer and low $\mathrm{CO}_{2}$ solubility wherein reactants and products are subsequently transferred among the electrodes. Unlike the liquid phase flow reactors, the use of solid electrolytes in a gas phase flow reactor does not require additional steps the final product separation, nominating as an emerging one. Interestingly, it is proved that controlling the stop-start motion of the electrolytes flow is also a crucial factor behind $\mathrm{HCOOH}$ production, allowing a sufficient time for $\mathrm{CO}_{2}$ gas molecules to effectively reduce. It is also realized as switching from the liquid-phase electrolysis to the gasphase is desired for industrial-scale applications. Besides, the different MEA type gas and liquid phase reactors have emerged for the electrochemical reduction of $\mathrm{CO}_{2}$ into $\mathrm{HCOO}^{-}$or $\mathrm{HCOOH}$ and the recirculation of by-products has been introduced to improve the efficiency of $\mathrm{HCOOH}$. The membraneless MR is formed with the accommodation of gas products; however, this is also prone to suffer from product crossover and the re-oxidation of products. Membrane-based $\mathrm{CO}_{2} \mathrm{R}$ electrolyzers are configured to minimize the distance between the electrodes, obviously called 'zero-gap', which in turn decrease the internal ohmic resistance and enhance the efficiency as well. Further, the gas fed zero-gap electrolyzer has been newly existing in the direction of large-scale applications but the $\mathrm{CO}_{2} \mathrm{R}$ toward $\mathrm{HCOOH}$ is at an initial stage. Despite the several improvements, all the reactors still show drawbacks that have to be addressed with further investigations. In particular, $\mathrm{CO}_{2} \mathrm{R}$ to $\mathrm{HCOO}^{-} / \mathrm{HCOOH}$ by MEA based flow reactors and gas fed zero-gap configurations have potential in the future to boost the current density and FE for the commercial commodity. All the reactors govern a similar electrochemical principle with $\mathrm{CO}_{2}$ reducing cathode, materials stream, and oxygen-generating anode. In these, the cathode holds special attention, carrying the electrocatalyst for 
the production of value-added chemicals (e.g., formic acid). The current scientific research also lacks in the anode design, which remains one of the biggest aspects to conquer the full cell overpotential. Moreover, the key points $(\mathrm{pH}$ of the electrolyte, ionic conductivity, selectivity, and swelling property) of different ion exchange membranes have been taken into the consideration and a very few reports are available on $\mathrm{HCOOH}$ by the $\mathrm{CO}_{2} \mathrm{R}$ process using BPM as compared to CEM and AEM. While screening the performance of different electrocatalysts $\mathrm{Pb}, \mathrm{Sn}, \mathrm{Bi}$, In, novel alloy combinations ( $\mathrm{Pb}-\mathrm{Sn}, \mathrm{Bi}-\mathrm{Sn}, \mathrm{Bi}-\mathrm{Sn}-\mathrm{In}$ ) have delivered promising results due to the unique morphologies and the aerogel designs. Importantly, aerogels have garnered numerous reactive sites (3D interconnected channels, abundant interfaces, and hydrophilic surfaces) for the selective detection of desired products. Hence, the futuristic improvements should also rely on the proper choice of the electrolyzers, membranes, and electrocatalysts to meet the target proposed by the techno-economic analyses (current density of $200 \mathrm{~mA} \mathrm{~cm}^{-2}$ and the reactor duration $20000 \mathrm{~h}$ ). As our ultimate motive of the global is freedom from energy shortage and pollution, it is also better to transition from electrochemical to photoelectrochemical $\mathrm{CO}_{2}$ reduction utilizing the abundant solar energy, which is clean, green, and renewable.

\section{Conflicts of interest}

Authors have not any conflict of interest.

\section{Acknowledgements}

Authors acknowledge GAP-308, funded by Ministry of Steel, Government of India.

\section{References}

1 S. Chatterjee, I. Dutta, Y. Lum, Z. Lai and K. W. Huang, Energy Environ. Sci., 2021, 14, 1194.

2 NOAA, Earth's $\mathrm{CO}_{2}$ home page, accessed on January 2, 2020.

3 I. E. Agency, Energy Technology Perspectives 2014, Paris Cedex, France, 2014.

4 Y. Y. Birdja, Electrocatalytic $\mathrm{CO}_{2}$ reduction toward liquid fuels: on heterogeneous electrocatalysts and heterogenized molecular catalysts, $\mathrm{PhD}$ thesis, Leiden Institute of Chemistry (LIC), Science, Leiden University, 2018.

5 J. Eppinger and K. W. Huang, ACS Energy Lett., 2017, 2, 188. 6 Niharika, Y. S. Chaudhary and S. Basu, $\mathrm{CO}_{2}$ Conversion into Chemicals and Fuel: India's Perspective, in Climate Change and Green Chemistry of $\mathrm{CO}_{2}$ Sequestration. Green Energy and Technol., ed. M. Goel, T. Satyanarayana, M. Sudhakar and D. P. Agrawal, Springer, 2021, ch. 8, pp. 105-122.

7 H. Yoshio, K. Katsuhei and S. Shin, Chem. Lett., 1985, 14, 1695.

8 H. Yoshio, K. Katsuhei, M. Akira and S. Shin, Chem. Lett., 1986, 15, 897.

9 K. Malik, S. Singh, A. Verma and S. Basu, Wiley Interdiscip. Rev.: Energy Environ., 2016, 6(4), 1.

10 G. Gag and S. Basu, Electrochim. Acta, 2015, 177, 359.
11 D. Chanda, R. A. Tufa, D. Aili and S. Basu, Nanotechnology, 2021, 33, 055403.

12 R. A. Tufa, D. Chanda, M. Ma, D. Aili, T. B. Demissie, J. Vaes, Q. Li, S. Liu and D. Pant, Appl. Energy, 2020, 277, 115557.

13 S. Verma, B. Kim, H. R. Jhong, S. Ma and P. J. Kenis, ChemSusChem, 2016, 9, 1972.

14 D. Du, R. Lan, J. Humphreys and S. Tao, J. Appl. Electrochem., 2017, 47, 661.

15 V. P. Roan, et al., Review of the research program of the freedom CAR and fuel partnership, 3rd report, National Academy of Sciences, The National Academies Press, Washington, DC, 2010.

$16 \mathrm{~J}$. Alazemi and J. Andrews, Renewable Sustainable Energy Rev., 2015, 48, 483.

17 J. M. Spurgeon and B. Kumar, Energy Environ. Sci., 2018, 11, 1536.

18 L. Fan, C. Xia, P. Zhu, Y. Lu and H. Wang, Nat. Commun., 2020, 11, 3633.

19 N. Han, Y. Wang, H. Yang, J. Deng, J. Wu and Y. Li, Nat. Commun., 2018, 9, 1320.

20 Q. Wang, M. Ma, S. Zhang, K. Lu, L. Fu, X. Liu and Y. Chen, ChemPlusChem, 2020, 85, 672.

21 H. Mistry, A. S. Varela, C. S. Bonifacio, I. Zegkinoglou, I. Sinev, Y. W. Choi, K. Kisslinger, E. A. Stach, J. C. Yang, P. Strasser and B. R. Cuenya, Nat. Commun., 2016, 7, 1.

22 N. Kumari, A. Haider, M. Agarwal, N. Sinha and S. Basu, J. Phys. Chem. C, 2016, 120(30), 16626.

23 M. Ma, K. Liu, J. Shen, R. Kas and W. A. Smith, ACS Energy Lett., 2018, 3, 1301.

24 N. Kumari, N. Sinha, A. Haider and S. Basu, Electrochim. Acta, 2015, 177, 21.

25 S. Liang, N. Altaf, L. Huang, Y. Gao and Q. Wang, J. $\mathrm{CO}_{2}$ Util., 2020, 35, 90.

26 S. Zhang, M. Sun, K. y. Wang, L. Cheng, S. Zhang and C. Wang, ACS Sustainable Chem. Eng., 2021, 9, 2358.

27 D. Pan, X. Ye, Y. Cao, S. Zhu, X. Chen, M. Chen, D. Zhang and G. Li, Appl. Surf. Sci., 2020, 511, 145497.

28 C. Zhao and J. Wang, Chem. Eng. J., 2016, 293, 161.

29 J. Du, A. Fiorani and Y. Einaga, Sustainable Energy Fuels, 2021, 5, 2590.

30 J. C. Li, Y. Kuang, Y. T. Meng, X. Tian, W. H. Hung, X. Zhang, A. W. Li, M. Q. Xu, W. Zhou, C. S. Ku, C. Y. Chiang, G. Zhu, J. Guo, X. Sun and H. Dai, J. Am. Chem. Soc., 2020, 142, 7276.

31 R. Lin, J. Guo, X. Li, P. Patel and A. Seifitokaldani, Catalysts, 2020, 10(473), 1.

32 W. Lee, Y. E. Kim, M. H. Youn, S. K. Jeong and K. T. Park, Angew. Chem., Int. Ed., 2018, 57, 6883.

33 C. Xia, P. Zhu, Q. Jiang, Y. Pan, W. Liang, E. Stavitsk, H. N. Alshareef and H. Wang, Nat. Energy, 2019, 4, 776.

34 C. M. Gabardo, A. Seifitokaldani, J. P. Edwards, C. T. Dinh, T. Burdyny, M. G. Kibria, C. P. O'Brien, E. H. Sargent and D. Sinton, Energy Environ. Sci., 2018, 11, 2531.

35 T. Burdyny and W. A. Smith, Energy Environ. Sci., 2019, 12, 1442. 
36 M. Ramdin, A. R. T. Morrison, M. Groen, R. Haperen, R. Kler, L. J. P. Broeke, J. P. M. Trusler, W. Jong and T. J. H. Vlugt, Ind. Eng. Chem. Res., 2019, 58, 1834.

37 J. J. Wu, F. G. Risalvato, P. P. Sharma, P. J. Pellechia, F. S. Ke and X. D. Zhou, J. Electrochem. Soc., 2013, 160, 953.

38 Irkham, S. Nagashima, M. Tomisaki and Y. Einaga, ACS Sustainable Chem. Eng., 2021, 9, 5298.

39 K. Natsui, H. Iwakawa, N. Ikemiya, K. Nakata and Y. Einaga, Angew. Chem., Int. Ed., 2018, 57, 2639.

40 M. E. Leonard, L. E. Clarke, A. Forner-Cuenca, S. M. Brown and F. R. Brushett, ChemSusChem, 2020, 13, 400-401.

41 L. C. Weng, A. T. Bell and A. Z. Weber, Phys. Chem. Chem. Phys., 2018, 20, 16973.

42 A. Seifitokaldani, C. M. Gabardo, T. Burdyny, C. T. Dinh, J. P. Edwards, M. G. Kibria, O. S. Bushuyev, S. O. Kelley, D. Sinton and E. H. Sargent, J. Am. Chem. Soc., 2018, 140, 3833.

43 C. Lee, B. Zhao, J. K. Lee, K. F. Fahy, K. Krause and A. Bazylak, iScience, 2020, 23, 101094.

44 Q. Gong, P. Ding, M. Xu, X. Zhu, M. Wang, J. Deng, Q. Ma, N. Han, Y. Zhu, J. Lu, Z. Feng, Y. Li, W. Zhou and Y. Li, Nat. Commun., 2019, 10, 2807.

45 Y. Chen, A. Vise, W. E. Klein, F. C. Cetinbas, D. J. Myers, W. A. Smith, T. G. Deutsch and K. C. Neyerlin, ACS Energy Lett., 2020, 5, 1825.

46 C. T. Dinh, F. P. García de Arquer, D. Sinton and E. H. Sargent, ACS Energy Lett., 2018, 3, 2835.

47 L. Delafontaine, T. Asset and P. Atanassov, ChemSusChem, 2020, 13, 1688.

48 Z. Yin, H. Peng, X. Wei, H. Zhou, J. Gong, M. Huai, L. Xiao, G. Wang, J. Lu and L. Zhuang, Energy Environ. Sci., 2019, 12, 2455.

49 G. Díaz-Sainz, M. Alvarez-Guerra, J. Solla-Gullón, L. GarcíaCruz, V. Montiel and A. Irabien, Catal. Today, 2020, 346, 58.

50 H. Yang, J. J. Kaczur, S. D. Sajjad and R. I. Masel, J. $\mathrm{CO}_{2}$ Util., 2017, 20, 208.

51 B. Thijs, J. Rongé and J. A. Martens, Sustainable Energy Fuels, 2021, 5, 1867.

52 S. Lee, H. Ju, R. Machunda, S. Uhm, J. K. Lee, H. J. Lee and J. Lee, J. Mater. Chem. A, 2015, 3, 3029.

53 G. O. Larrazábal, P. Strøm-Hansen, J. P. Heli, K. Zeiter, K. T. Therkildsen, I. Chorkendorff and B. Seger, ACS Appl. Mater. Interfaces, 2019, 11, 41281.

54 A. Patru, T. Binninger, B. Pribyl and T. J. Schmidt, J. Electrochem. Soc., 2019, 166(2), F34.

55 H. Pan and C. J. Barile, Energy Environ. Sci., 2020, 13, 3567.

56 D. T. Whipple, E. C. Finke and P. J. A. Kenis, Electrochem. Solid-State Lett., 2010, 13, B109.

57 X. Lu, D. Y. C. Leung, H. Wang, M. M. Maroto-Valer and J. A. Xuan, Renewable Energy, 2016, 95, 277.

58 F. P. G. D. Arquer, O. S. Bushuyev, P. D. Luna, C. T. Dinh, A. Seifitokaldani, M. I. Saidaminov, C. S. Tan, L. N. Quan, A. Proppe, M. G. Kibria, S. O. Kelley, D. Sinton and E. H. Sargent, Adv. Mater., 2018, 30, 1802858.

59 A. Del Castillo, M. Alvarez-Guerra, J. Solla-Gullón, A. Sáez, V. Montiel and A. Irabien, Appl. Energy, 2015, 157, 165.
60 B. De Mot, M. Ramdin, J. Hereijgers, T. J. H. Vlugt and T. Breugelmans, ChemElectroChem, 2020, 7, 3839.

61 J. Huang, X. Guo, J. Yang and L. Wang, J. $\mathrm{CO}_{2}$ Util., 2020, 38, 32.

62 Q. Lai, W. Yuan, W. Huang and G. Yuan, Appl. Surf. Sci., 2020, 508, 145221.

63 W. Ma, S. Xie, X. G. Zhang, F. Sun, J. Kang, Z. Jiang, Q. Zhang, D. Y. Wu and Y. Wang, Nat. Commun., 2019, 10, 1.

64 R. Kortlever, I. Peters, S. Koper and M. T. M. Koper, ACS Catal., 2015, 5, 3916.

65 S. X. Guo, Y. Zhang, X. Zhang, C. D. Easton, D. R. MacFarlane and J. Zhang, ChemSusChem, 2019, 12, 1091.

66 S. R. Narayanan, B. Haines, J. Soler and T. I. Valdez, J. Electrochem. Soc., 2011, 158, 167.

67 K. Bejtka, J. Zeng, A. Sacco, M. Castellino, S. Hernández, M. A. Farkhondehfal, U. Savino, S. Ansaloni, C. F. Pirri and A. Chiodoni, ACS Appl. Energy Mater., 2019, 2, 3081.

68 Q. Zhang, Y. Zhang, J. Mao, J. Liu, Y. Zhou, D. Guay and J. Qiao, ChemSusChem, 2019, 12, 1443.

69 N. Furuya, T. Yamazaki and M. Shibata, J. Electroanal. Chem., 1997, 431, 39.

70 J. Wang, J. Zou, X. Hu, S. Ning, X. Wang, X. Kang and S. Chen, J. Mater. Chem. A, 2019, 7, 27514.

71 A. Del Castillo, M. Alvarez-Guerra, J. Solla-Gullón, A. Sáez, V. Montiel and A. Irabien, J. $\mathrm{CO}_{2}$ Util., 2017, 18, 222.

72 D. Kopljar, N. Wagner and E. Klemm, Chem. Eng. Technol., 2016, 39, 2042.

73 L. Ma, S. Fan, D. Zhen, X. Wu, S. Liu, J. Lin, S. Huang, W. Chen and G. He, Ind. Eng. Chem. Res., 2017, 56, 10242.

74 H. Xiang, H. A. Miller, M. Bellini, H. Christensen, K. Scott, S. Rasulac and E. H. Yu, Sustainable Energy Fuels, 2020, 4, 277.

75 R. Sinha, A. Bisht, S. Rarotra and T. K. Mandal, Ind. Eng. Chem. Res., 2020, 59, 1737.

76 C. Liang, B. Kim, S. Yang, Y. Liu, C. F. Woellner, Z. Li, R. Vajtai, W. Yang, J. Wu, P. J. A. Kenis and P. M. Ajayan, J. Mater. Chem. A, 2018, 6, 10313.

77 N. Gutierrez-Guerra, L. Moreno-Lopez, J. C. Serrano-Ruiz, J. L. Valverde and A. de Lucas- Consuegra, Appl. Catal., B, 2016, 188, 272.

78 A. Patru, T. Binninger, B. Pribyl and T. J. Schmidt, J. Electrochem. Soc., 2019, 166, 34.

79 D. A. Salvatore, D. M. Weekes, J. He, K. E. Dettelbach, Y. C. Li and T. E. Mallouk, ACS Energy Lett., 2018, 3, 149.

80 E. K. Unnikrishnan, S. D. Kumar and B. Maiti, J. Membr. Sci., 1997, 137, 133.

81 R. L. Cook, R. C. MacDuff and A. F. Sammells, J. Electrochem. Soc., 1990, 137, 187.

82 H. Li and C. Oloman, J. Appl. Electrochem., 2007, 37, 1107.

83 A. D. Mohanty, S. E. Tignor, J. A. Krause, Y. K. Choe and C. Bae, Macromolecules, 2016, 49, 3361.

84 M. Ma, E. L. Clark, K. T. Therkildsen, S. Dalsgaard, I. Chorkendorff and B. Seger, Energy Environ. Sci., 2020, 13, 977.

85 J. J. Kaczur, H. Yang, Z. Liu, S. D. Sajjad and R. I. Masel, Front. Chem., 2018, 6, 1. 
86 D. A. Vermaas and W. A. Smith, ACS Energy Lett., 2016, 1, 1143.

87 R. Simons, Electrochim. Acta, 1986, 31, 1175.

88 R. Simons, J. Membr. Sci., 1993, 78, 13.

89 Y. C. Li, Z. Yan, J. Hitt, R. Wycisk, P. N. Pintauro and T. E. Mallouk, Adv. Sustainable Syst., 2018, 2, 1700187.

90 Y. C. Li, D. Zhou, Z. Yan, R. H. Goncalves, D. A. Salvatore and C. P. Berlinguette, ACS Energy Lett., 2016, 1, 1149.

91 X. Zhou, R. Liu, K. Sun, Y. Chen, E. Verlage and S. A. Francis, ACS Energy Lett., 2016, 1, 764.

92 Y. Fu, Y. Li, X. Zhang, Y. Liu, J. Qiao and J. Zhang, Appl. Energy, 2016, 175, 536.

93 B. C. Marepally, C. Ampelli, C. Genovese, F. Tavella, E. A. Quadrelli and S. Perathoner, J. $\mathrm{CO}_{2}$ Util., 2020, 35, 194.

94 J. J. Kaczur, H. Yang, Z. Liu, S. D. Sajjad and R. I. Masel, Front. Chem., 2018, 6, 1.

95 X. Lu, D. Y. C. Leung, H. Wang and J. Xuan, Appl. Energy, 2017, 194, 549.

96 W. Lee, Y. E. Kim, M. H. Youn, S. K. Jeong and K. T. Park, Angew. Chem., Int. Ed., 2018, 57(23), 6883.

97 M. Moradzaman, C. S. Martınezb and G. Mul, Sustainable Energy Fuels, 2020, 4, 5195.

98 J. J. Kaczur and D. W. Cawlfield, US Pat., 1992, 5,092,970.

99 L. Su, S. Pei, L. Li, H. Li, Y. Zhang, W. Yu and C. Zhou, Int. J. Hydrogen Energy, 2009, 34, 6892.

100 R. I. Masel, Q. Chen, Z. Liu and R. Kutz, US Pat., 2016, $9,370,773$.

101 F. Wang, B. Xue, S. Zhou, J. Zheng, S. Li, S. Zhang and T. A. Sherazi, J. Membr. Sci., 2019, 591, 117334.

102 S. Chabi, A. G. Wright, S. Holdcroft and M. S. Freund, ACS Appl. Mater. Interfaces, 2017, 9(32), 26749.

103 J. Pan, L. Hou, Q. Wang, Y. He, L. Wu, A. N. Mondal and T. Xu, Mater. Chem. Phys., 2017, 186, 484.

104 Y. Hori, H. Wakebe, T. Tsukamoto and O. Koga, Electrochim. Acta, 1994, 39, 1833.

105 N. Kumari, M. A. Haider and S. Baisu, Mechanism of Catalytic and Electrocatalytic $\mathrm{CO}_{2}$ Reduction to Fuels and Chemicals, in Electrochemical Reduction of Carbon Dioxide: Fundamentals and Technologies, ed. J. Qiao, Y. Liu and J. Zhang, CRC Press, 2016, ch. 2.

106 N. Han, P. Ding, L. He, Y. Li and Y. Li, Adv. Energy Mater., 2019, 1902338, 1.

107 H. Noda, S. Ikeda and Y. Oda, Bull. Chem. Soc. Jpn., 1990, 63, 2459.

108 F. Köleli, T. Atilan, N. Palamut, A. M. Gizir, R. Aydin and C. H. Hamann, J. Appl. Electrochem., 2003, 33, 447.

109 Z. Zhang, C. Liu, J. T. Brosnahan, H. Zhou, W. Xu and S. Zhang, J. Mater. Chem. A, 2019, 7, 23775.

110 Y. Xing, M. Cui, P. Fan, J. Ren, C. Zhang, N. Li, X. Wen and X. Ji, Mater. Chem. Phys., 2019, 237, 121826.

111 P. Widiatmoko, I. Nurdin, H. Devianto, B. Prakarsa and H. Hudoyo, IOP Conf. Ser.: Mater. Sci. Eng., 2020, 823, 012053.

112 S. Basu, D. Biswal and A. Shegonkar, J. $\mathrm{CO}_{2}$ Util., 2017, 18, 80.
113 T. Tsujiguchi, Y. Kawabe, S. Jeong, T. Ohto, S. Kukunuri, H. Kuramochi, Y. Takahashi, T. Nishiuchi, H. Masuda, M. Wakisaka, K. Hu, G. Elumalai, J. Fujita and Y. Ito, ACS Catal., 2021, 11, 3310.

114 G. Wen, D. U. Lee, B. Ren, F. M. Hassan, G. Jiang, Z. P. Cano, J. Gostick, E. Croiset, Z. Bai, L. Yang and Z. Chen, Adv. Energy Mater., 2018, 1802427.

115 S. Ning, J. Wang, D. Xiang, S. Huang, W. Chen, S. Chen and X. Kang, J. Catal., 2021, 399, 67.

116 Y. Ito, S. Kukunuri, S. Jeong, G. Elumalai, A. A. H. Tajuddin, Z. Xi, K. Hu and T. Ohto, ACS Appl. Energy Mater., 2021, 4, 7122.

117 S. Y. Komatsu, T. Y. Hiraga, M. Tanaka and A. Kunugi, Denki Kagaku, 1995, 63, 217.

118 W. Ma, J. Bu, Z. Liu, C. Yan, Y. Yao, N. Chang, H. Zhang, T. Wang and J. Zhang, Adv. Funct. Mater., 2020, 2006704.

119 Q. Li, Y. Zhang, X. Zhang, H. Wang, Q. Li, J. Sheng, J. Yi, Y. Liu and J. Zhang, Ind. Eng. Chem. Res., 2020, 59, 6806.

120 Z. Wu, H. Wu, W. Cai, Z. Wen, B. Jia, L. Wang, W. Jin and T. Ma, Angew. Chem., Int. Ed., 2021, 60, 12554.

121 P. Hou, X. Wang and P. Kang, J. CO Util., 2021, 45, 101449. 122 Z. Bitar, A. Fecant, E. Trela-Baudot, S. Chardon-Noblat and D. Pasquier, Appl. Catal., B, 2016, 189, 172.

123 X. Teng, Y. Niu, S. Gong, M. Xu, X. Liu, L. Ji and Z. Chen, Mater. Chem. Front., 2021, 5, 6618.

124 J. Li, J. Li, X. Liu, J. Chen, P. Tian, S. Dai, M. Zhu and Y. F. Han, Appl. Catal., B, 2021, 298, 120581.

125 R. Masel, R. Ni, Z. Liu, Q. Chen, R. Kutz, L. Nereng and K. Lewinski, Energy Procedia, 2014, 63, 7959.

126 Mantra Venture Group, ERC and MRFC Technology, Mantra Venture Group, Surrey, Canada, 2014, retrieved from https://1stdirectory.co.uk/_assets/files_comp/9a5be6a3bb42-4244-9780-2f9a2a7dc3dc.pdf.

127 Korea Carbon Capture and Storage Association, Analysis of domestic and overseas $\mathrm{CO}_{2}$ utilization technology for creating carbon dioxide utilization industry, Korea Carbon Capture and Storage Association, Republic of Korea, 2015, retrieved from http://www.prism.go.kr/homepage/ researchCommon/downloadResearchAttachFile.do; jsessionid $=$ D1ECC5637B87A8758E5D 61977F33E73E.node02?work_key $=001 \&$ file_type $=$ CPR\&seq_no $=001 \&$ pdf_conv_yn=N\&research_id=1450000201500157.

128 N. Sridhar, D. Hill, A. Agarwal, Y. Zhai and E. Hektor, Carbon dioxide utilization, Electrochemical conversion of $\mathrm{CO}_{2}$-opportunities and challenges, Position paper 07, Det Norske Veritas, Høvik, Norway, 2011.

129 P. De Luna, C. Hahn, D. Higgins, S. A. Jaffer, T. F. Jaramillo and E. H. Sargent, Science, 2019, 364, 1.

130 G. O. Larrazábal, A. J. Martín and J. P. Ramírez, J. Phys. Chem. Lett., 2017, 8, 3933.

131 O. G. Sánchez, Y. Y. Birdja, M. Bulut, J. Vaes, T. Breugelmans and D. Pant, Curr. Opin. Green Sustain. Chem., 2019, 16, 47. 